\title{
Scalable Room-Temperature Synthesis of Highly Robust Ethane-Selective MOFs for Efficient Ethylene Purification
}

\author{
Shubo Geng, ${ }^{1}$ En Lin, ${ }^{1}$ Xia Li, ${ }^{3}$ Wansheng Liu, ${ }^{1}$ Ting Wang, ${ }^{1}$ Zhifang Wang, ${ }^{1}$ \\ Debobroto Sensharma, ${ }^{3}$ Shaza Darwish, ${ }^{3}$ Yassin H. Andaloussi, ${ }^{3}$ Tony Pham, ${ }^{4}$ Peng \\ Cheng, ${ }^{1}$ Michael J. Zaworotko, ${ }^{3}$ Yao Chen, ${ }^{2,5}$ and Zhenjie Zhang ${ }^{*}, 1,2$ \\ ${ }^{1}$ College of Chemistry, Nankai University, Tianjin 300071, P. R. China \\ ${ }^{2}$ State Key Laboratory of Medicinal Chemical biology, Nankai University, Tianjin 300071, P. R. China \\ ${ }^{3}$ Department of Chemical Sciences, Bernal Institute University of Limerick, Limerick V94T9PX, \\ Republic of Ireland \\ ${ }^{4}$ Department of Chemistry, University of South Florida, 4202 East Fowler Avenue, Tampa, Florida \\ 33620, United States \\ ${ }^{5}$ College of Pharmacy, Nankai University, Tianjin 300071, P. R. China
}

\section{Materials and Physical Measurements}

All reagents and solvents were purchased from companies commercially and used without further purification. Thermogravimetric analysis (TGA) was measured from $30^{\circ} \mathrm{C}$ to $800{ }^{\circ} \mathrm{C}$ under a nitrogen $\left(\mathrm{N}_{2}\right)$ atmosphere with a heating rate of $10^{\circ} \mathrm{C} / \mathrm{min}$ by NETZSCH TG-209. Powder $\mathrm{x}$-ray diffraction (PXRD) data were carried out by Rigaku Ultima IV diffractometer $(40 \mathrm{kV}, 40 \mathrm{~mA}$, $\mathrm{CuK} \alpha 1,2 \lambda=1.5418 \AA$ ), and scanning over the range from $2^{\circ}$ to $40^{\circ}$ with a step size of $0.02\left(^{\circ}\right)$ and a rate of $2 \%$ min. The scanning electron microscopy (SEM) images were obtained on HITACHI S4800. Fourier transform infrared spectra (FT-IR) were recorded on Bruker ALPHAI.

\section{Synthesis of ligands}

2-bromoimidazole-4, 5-dicarbonitrile. To a $500 \mathrm{~mL}$ flask 4, 5-dicyanoimidazole (30 mmol $3.54 \mathrm{~g}$ ) was added to $1 \mathrm{M} \mathrm{NaOH}$ solution $(80 \mathrm{~mL})$ and stirred for $1 \mathrm{~h}$ at room temperature. Then bromine $(107 \mathrm{mmol}, 5.5 \mathrm{~mL})$ was added to the mixture dropwise slowly. The resultant mixture was stirred overnight at ambient temperature, and a white precipitate was filtered and washed by water, 2-bromo-4, 5-dicyanoimidazole was obtained as a white powder in a yield of $80 \% .{ }^{13} \mathrm{C}$ NMR (125 MHz, DMSO- $\left.d_{6}\right) \delta(\mathrm{ppm}) 126.73,118.15,112.06$.

2-methylimidazole-4, 5-dicarbonitrile. Triethyl orthoacetate $(3.24 \mathrm{~mL})$, diaminomaleonitrile $(1.753 \mathrm{~g})$ and $50 \mathrm{~mL}$ acetonitrile were added to a $500 \mathrm{~mL}$ flask, stirred for two days at $80^{\circ} \mathrm{C}$, then the solvent was removed and $50 \mathrm{~mL}$ EtOH was added to the residue stirred for one day at $80^{\circ} \mathrm{C}$, $\mathrm{EtOH}$ was removed and the white product was obtained by recrystallization in $\mathrm{MeOH}$ in a yield of $80 \%$. ${ }^{1} \mathrm{H}$ NMR (300 MHz, DMSO- $\left.d_{6}\right) \delta$ (ppm) 2.39(s).

\section{Synthesis of NKMOF-8-Br and NKMOF-8-Me powders}

1.06 mmol ligands (2-bromoimidazole- or 2-methylimidazole-4, 5-dicarbonitrile) and $\mathrm{CuI}$ with equal molar ratio were fully dissolved by acetonitrile $(50 \mathrm{~mL})$ in a flask, $10 \mathrm{mmol}(1.5 \mathrm{~mL})$ 
trimethylamine was added slowly to the mixture and stirred at ambient temperature, and white solid was precipitated completely in one minute. The resulting products were obtained by filtration, and the filtrate can be reused in seven cycles for the synthesis of NKMOF-8-Br and -Me with yields over $95 \%$.

\section{Synthesis of NKMOF-8-Br and NKMOF-8-Me crystals}

NKMOF-8-Br crystal was prepared by solvothermal reaction of equimolar 2-bromoimidazole-4, 5-dicarbonitrile $(0.3 \mathrm{mmol}, 58 \mathrm{mg})$ and $\mathrm{CuI}(0.3 \mathrm{mmol}, 57 \mathrm{mg})$ in acetonitrile $(10 \mathrm{~mL})$ The solution was sealed in a $35 \mathrm{~mL}$ Teflon-lined autoclave and heated at 100 ${ }^{\circ} \mathrm{C}$ for one day ( $65 \%$ yield).

NKMOF-8-Me crystals are yielded through slow volatilization of the following solution (20\% yield): mixing Formic acid $(0.3 \mathrm{~mL})$ with NKMOF-8-Me $(50 \mathrm{mg})$ powder and dissolved in $2 \mathrm{~mL}$ acetonitrile).

\section{Scale-up synthesis of NKMOF-8-Br and NKMOF-8-Me powders}

$34 \mathrm{mmol} \mathrm{CuI} \mathrm{was} \mathrm{stirred} \mathrm{in} \mathrm{acetonitrile}(800 \mathrm{~mL})$ until it was fully dissolved. And $10 \mathrm{~mL}$ trimethylamine and 34 mmol ligands (2-bromoimidazole- or 2-methylimidazole-4, 5-dicarbonitrile) were dissolved in acetonitrile $(150 \mathrm{~mL})$. The above solution was added into $\mathrm{CuI}$ acetonitrile solution, and white precipitates formed immediately. After stirring for three minutes, the white product was obtained by filtration, washed with acetonitrile for three times, and then dried in an oven at $80{ }^{\circ} \mathrm{C}(\sim 10 \mathrm{~g}, 91 \%$ yield for NKMOF-8-Br; $\sim 12 \mathrm{~g}, 90 \%$ yield for NKMOF-8-Me). The dried products were heated at $100{ }^{\circ} \mathrm{C}$ under dynamic vacuum conditions for $8 \mathrm{~h}$ to remove acetonitrile to obtain the activated MOFs.

\section{Single-Crystal X-ray Crystallography}

Single-crystal X-ray diffraction data of NKMOF-8-Br, NKMOF-8-Me, $\mathbf{C}_{2} \mathrm{H}_{4} @ \mathbf{N K M O F - 8 - B r}$ and $\mathbf{C}_{2} \mathbf{H}_{6} @ N K M O F-8-B r$ were collected on SuperNova (Mo) X-ray Source with micro-focus sealed X-ray tube at $120 \mathrm{~K}$ under $\mathrm{N}_{2}$ flow via an Oxford Cryo stream system. All structures were solved and refined by using Olex2 with 'XS' and 'XL' plug-in. These crystal data are summarized in Table S1. And the activated NKMOF-8-Br crystals were filled with ethane or ethylene via an ethane or ethylene balloon at room temperature. Then the single crystal of $\mathbf{C}_{2} \mathbf{H}_{6} @ N K M O F-8-B r$ or $\mathbf{C}_{2} \mathbf{H}_{4} @ N K M O F-8-B r$ was doped into Paratone-N oil, mounted via a loop and quickly transferred to diffractometer and single crystal x-ray diffraction (SCXRD) was collected at $120 \mathrm{~K}$ under $\mathrm{N}_{2}$ flow.

\section{Gas Sorption Measurements}

The gas adsorption isotherms were measured on a Micromeritics ASAP 2460 surface area analyzer. Before the gas sorption analysis, NKMOF-8-Br and NKMOF-8-Me were heated at 100 ${ }^{\circ} \mathrm{C}$ under dynamic vacuum conditions for $8 \mathrm{~h}$ to remove acetonitrile. MCIF-1 was soaked in dichloromethane until guest solvent, acetonitrile, was exchanged totally. Then MCIF-1 was collected by centrifugation and heated at room temperature under dynamic vacuum conditions for $8 \mathrm{~h} . \mathbf{C u}(\mathbf{Q c})_{2}$ was activated according to the literature. ${ }^{\mathrm{S} 1} \mathbf{P C N}-250$ was activated according to the literature. ${ }^{\mathrm{S} 11}$ MIL-142A was activated according to the literature. ${ }^{\mathrm{S} 10}$ The testing temperatures, 77 K, 87 K, $273 \mathrm{~K}, 298 \mathrm{~K}$, are maintained by liquid nitrogen, liquid argon, ice-water bath, and water 
bath, respectively.

Table S1. Crystal data and structural refinement

\begin{tabular}{|c|c|c|c|c|}
\hline & $\mathrm{C}_{2} \mathrm{H}_{4} @$ NKMOF-Br & $\mathrm{C}_{2} \mathrm{H}_{6} @$ NKMOF-8-Br & NKMOF-8-Br & NKMOF-8-Me \\
\hline Identification code & $\mathrm{C}_{2} \mathrm{H}_{4} @ \mathrm{NKMOF}-8-\mathrm{Br}$ & $\mathrm{C}_{2} \mathrm{H}_{6} @$ NKMOF-8-Br & NKMOF-8-Br & NKMOF-8-Me \\
\hline Empirical formula & $\mathrm{C}_{2.75} \mathrm{H}_{0.5} \mathrm{Br}_{0.5} \mathrm{Cu}_{0.5} \mathrm{~N}_{2}$ & $\mathrm{C}_{3} \mathrm{H}_{1.5} \mathrm{Br}_{0.5} \mathrm{Cu}_{0.5} \mathrm{~N}_{2}$ & $\mathrm{C}_{2.5} \mathrm{Br}_{0.5} \mathrm{Cu}_{0.5} \mathrm{~N}_{2}$ & $\mathrm{C}_{3.25} \mathrm{H}_{2.25} \mathrm{Cu}_{0.5} \mathrm{~N}_{2}$ \\
\hline Formula weight & 133.28 & 137.29 & 129.77 & 101.09 \\
\hline Temperature/K & 120 & 120 & 120 & 120 \\
\hline Crystal system & orthorhombic & orthorhombic & orthorhombic & orthorhombic \\
\hline Space group & Pnna & Pnna & Pnna & Pnna \\
\hline $\mathbf{a} / \AA$ & $10.9748(3)$ & $10.9745(13)$ & $11.0306(13)$ & $10.9436(11)$ \\
\hline $\mathbf{b} / \mathbf{A}$ & $8.5812(3)$ & $8.6056(11)$ & $8.6572(14)$ & $8.6154(10)$ \\
\hline $\mathbf{c} / \mathbf{A}$ & $10.0596(4)$ & $10.0876(14)$ & $10.0114(19)$ & $10.0156(9)$ \\
\hline $\boldsymbol{\alpha} /{ }^{\circ}$ & 90 & 90 & 90 & 90 \\
\hline$\beta /{ }^{\circ}$ & 90 & 90 & 90 & 90 \\
\hline$\gamma /{ }^{\circ}$ & 90 & 90 & 90 & 90 \\
\hline Volume $/ \AA^{3}$ & $947.38(6)$ & $952.7(2)$ & $956.0(3)$ & $944.30(16)$ \\
\hline $\mathbf{Z}$ & 8 & 8 & 8 & 8 \\
\hline $\mathbf{u} / \mathbf{m m}^{-1}$ & 6.469 & 6.436 & 6.408 & 2.260 \\
\hline $\mathbf{F}(000)$ & 504 & 524 & 488 & 402.0 \\
\hline Goodness-of-fit & 1.079 & 1.056 & 1.098 & 1.043 \\
\hline Final $\mathbf{R}$ & 0.0205 & 0.0589 & 0.0344 & 0.1003 \\
\hline$[\mathrm{I}>=\mathbf{2 \sigma}(\mathrm{I})]$ & $w_{2}=0.0538$ & $w_{2}=0.1377$ & $w_{2}=0.0800$ & $\mathrm{wR}_{2}=0.2541$ \\
\hline CCDC number & 2061594 & 2061593 & 2061591 & 2061969 \\
\hline
\end{tabular}


Table S2. Summary of the adsorption data of various $\mathrm{C}_{2} \mathrm{H}_{6}$-selective MOFs.

\begin{tabular}{|c|c|c|c|c|c|c|c|c|c|}
\hline MOFs & Pore size $(\AA)$ & $\begin{array}{c}\text { BET } \\
\left(\mathbf{m}^{2} \mathbf{g}^{-1}\right)\end{array}$ & $\begin{array}{c}\mathrm{C}_{2} \mathrm{H}_{6} \text { uptake } \\
{ }^{\mathrm{a}}\left(\mathrm{mmol} \mathrm{g}^{-1}\right)\end{array}$ & $\begin{array}{c}\mathrm{C}_{2} \mathrm{H}_{4} \text { uptake a } \\
\left(\mathrm{mmol} \mathrm{g}^{-1}\right)\end{array}$ & $\begin{array}{l}\text { unsaturated } \\
\text { metal sites }\end{array}$ & Stability & $\begin{array}{c}\text { Selectivity } \\
\text { b }\end{array}$ & $\begin{array}{r}\text { Qst }^{\mathrm{c}} \\
(\mathrm{kJ} \\
\left.\mathrm{mol}^{-1}\right)\end{array}$ & Reference \\
\hline NKMOF-8-Br & 6.6 & 352 & 4.22 & 3.67 & none & $\begin{array}{l}\text { highly } \\
\text { thermal/chemical/ } \\
\text { hydrolytic stability }\end{array}$ & 2.65 & $40.8 / 33.6$ & $\begin{array}{l}\text { This } \\
\text { work }\end{array}$ \\
\hline NKMOF-8-Me & 5.9 & 655 & 4.82 & 4.67 & none & $\begin{array}{l}\text { highly } \\
\text { thermal/chemical/ } \\
\text { hydrolytic stability }\end{array}$ & 1.88 & $38.4 / 37.6$ & $\begin{array}{l}\text { This } \\
\text { work }\end{array}$ \\
\hline $\mathrm{Cu}(\mathrm{Qc})_{2}$ & 3.3 & 240 & 1.85 & 0.78 & none & limited stability & 3.4 & $29 / 25.4$ & S1 \\
\hline MUF-15 & $\begin{array}{l}8.5 \times 3.5 \\
7 \times 3.8 \\
3.2 \times 1.2\end{array}$ & 1130 & 4.69 & 4.15 & existence & limited stability & $\begin{array}{l}1.96 \\
(293 \mathrm{~K})\end{array}$ & $29.2 / 28.2$ & S2 \\
\hline MAF-49 & $3.0-3.3$ & N/A & 1.72 & 1.69 & none & $\begin{array}{l}\text { highly } \\
\text { thermal/chemical/ } \\
\text { hydrolytic stability }\end{array}$ & 2.7 & $-1-$ & $\mathrm{S} 1$ and $\mathrm{S} 3$ \\
\hline ZIF-4 & N/A & N/A & 2.3 & 2.2 & none & limited stability & 2.1 & $-/-$ & S4 \\
\hline ZIF-7 & $\mathrm{N} / \mathrm{A}$ & N/A & 2.00 & 1.82 & none & limited stability & 1.5 & $-/-$ & S5 \\
\hline ZIF-8 & 3.4 & 1844 & 2.54 & 1.43 & none & $\begin{array}{l}\text { highly } \\
\text { thermal/chemical/ } \\
\text { hydrolytic stability }\end{array}$ & 1.8 & $17.2 / 16.1$ & S6 \\
\hline ZJU-120a & 4.4 & 1597 & 4.91 & 3.93 & none & $\begin{array}{c}\text { highly thermal } \\
\text { stability }\end{array}$ & $\begin{array}{c}2.74 \\
(296 \mathrm{~K})\end{array}$ & $27.6 / 17$ & S7 \\
\hline $\mathrm{Fe}_{2}\left(\mathrm{O}_{2}\right)($ dobdc) & N/A & 1073 & 3.4 & 2.6 & none & limited stability & 4.4 & $66.8 / 36.5$ & S8 \\
\hline $\mathrm{Ni(bdc)(ted)})_{0.5}$ & $\begin{array}{l}7.6 \times 7.6 \\
5.1 \times 3.7\end{array}$ & 1701 & 5.0 & 3.4 & none & $\begin{array}{c}\text { highly thermal } \\
\text { stability }\end{array}$ & 2 & $21.5 / 18.4$ & S9 \\
\hline MIL-142A & 10 & 1555 & 3.80 & 2.90 & existence & limited stability & 1.5 & $27.3 / 25.1$ & $\mathrm{~S} 10$ \\
\hline PCN-250 & 5.5 and 9.6 & 1470 & 5.21 & 4.22 & existence & limited stability & 1.9 & $24 / 21$ & S11 \\
\hline JNU-2 & $3.4,4.6,6.7$ & 1219 & 4.1 & 3.6 & existence & limited stability & 1.6 & $29.4 / 26.7$ & $\mathrm{~S} 12$ \\
\hline NTU-25 & $\sim 8.5$ & 398 & $\sim 4.38$ & $\sim 4.24$ & none & $\begin{array}{c}\text { highly } \\
\text { thermal/chemical } \\
\text { stability }\end{array}$ & - & $\sim 31 / 27$ & S13 \\
\hline IRMOF-8 & 16.2 & 1360 & 5.02 & 4.78 & none & $\begin{array}{c}\text { highly thermal } \\
\text { stability }\end{array}$ & 1.8 & - & S1 \\
\hline NPU-1 & 7.4 & 1557 & 4.5 & 4.2 & none & $\begin{array}{c}\text { highly thermal } \\
\text { stability }\end{array}$ & 1.32 & $29.1 / 23.9$ & S14 \\
\hline MCIF-1 & 9.26 & 1437 & 2.40 & 2.19 & none & limited stability & 1.61 & $30.0 / 29.0$ & S15 \\
\hline
\end{tabular}


a Adsorption amount at 1 bar in isotherms.

b From IAST calculation $\mathrm{C}_{2} \mathrm{H}_{6} / \mathrm{C}_{2} \mathrm{H}_{4}(1: 1, \mathrm{v} / \mathrm{v})$ mixture.

(a)

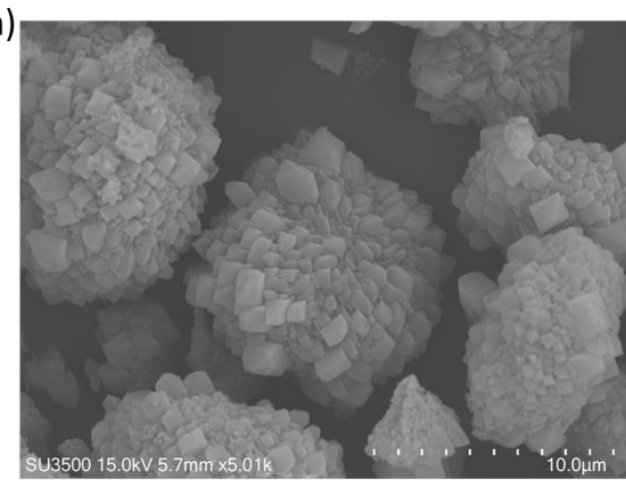

(b)

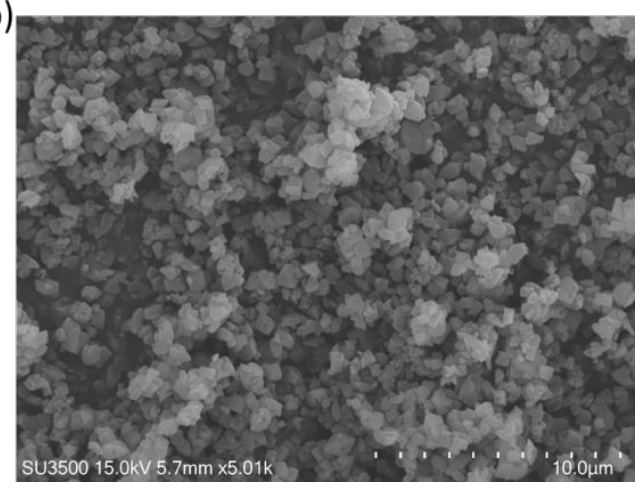

Figure S1. SEM images of NKMOF-8-Br (left) and NKMOF-8-Me (right).

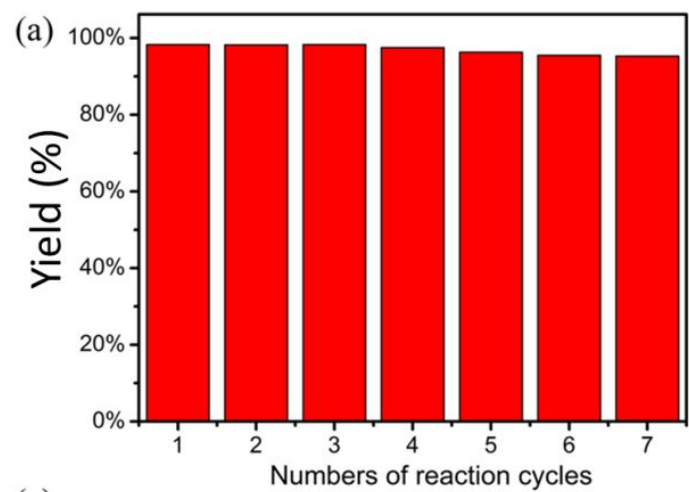

(c)

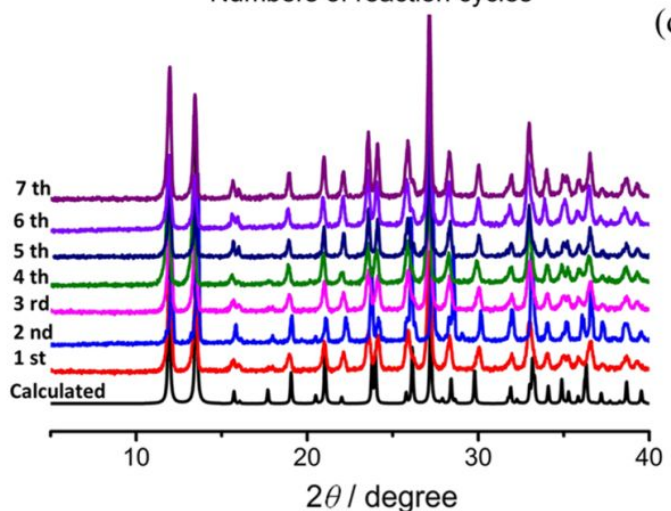

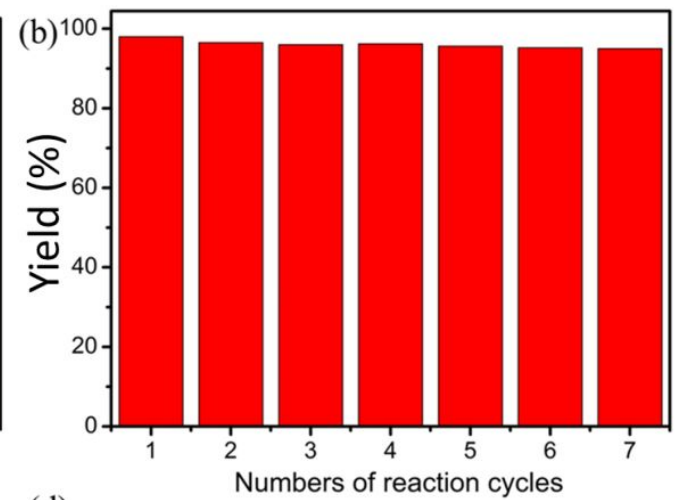

(d)



Figure S2. (a, b) Yields of synthesis of NKMOF-8-Br and -Me by using recycled solvents. (c, d) PXRD of synthesis of NKMOF-8-Br and-Me using recycled solvents. 

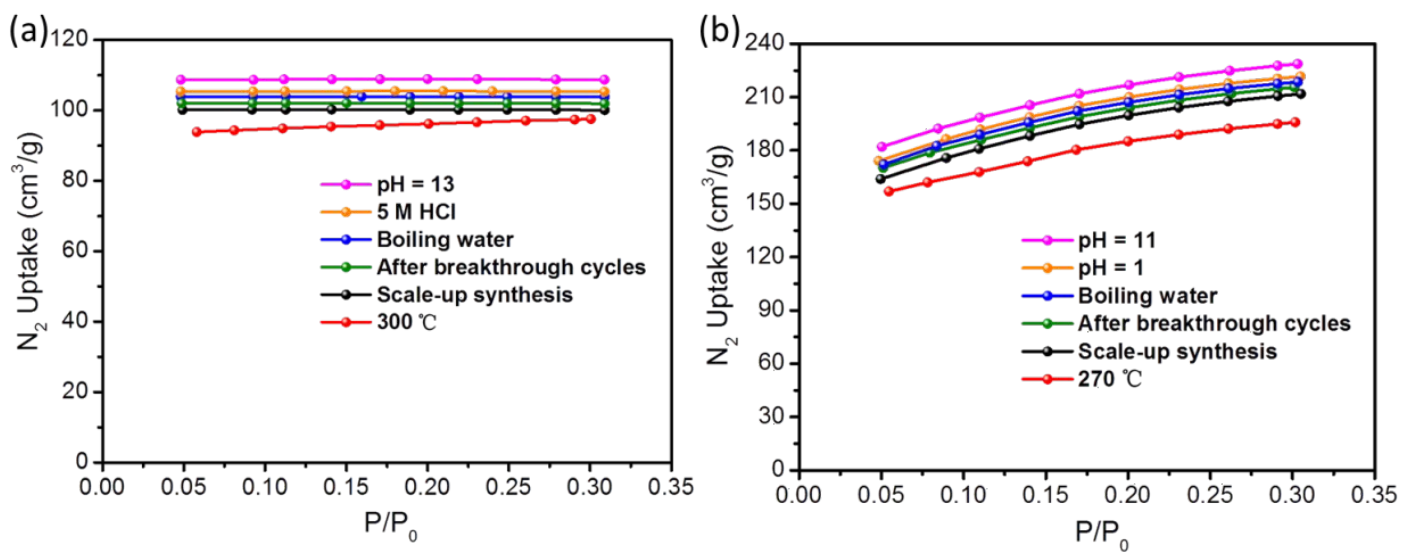

Figure S3. (a, b) BET of NKMOF-8-Br (left) and -Me (right) after various treatments and large-scale synthesis.



Figure S4. TGA curves of NKMOF-8-Br and NKMOF-8-Me.
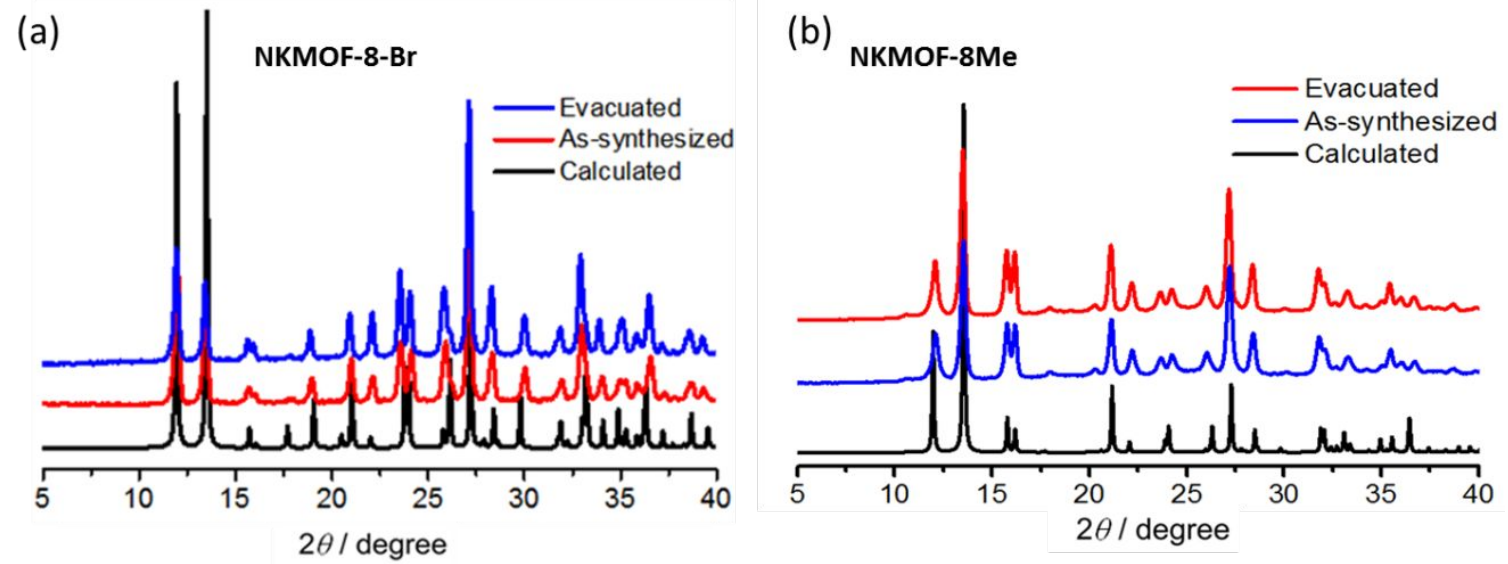

Figure S5. (a, b) PXRD of evacuated, as-synthesized, and calculated NKMOF-8-Br (left) and NKMOF-8-Me (right). 


\section{Adsorption Kinetics Measurement}

Evaluation of 0-1 bar adsorption and desorption kinetics were carried out using a Hiden Isochema XEMIS microbalance. High-purity gases were used as received from BOC Gases Ireland, $\mathrm{C}_{2} \mathrm{H}_{4}$ research grade (99.92\%), and $\mathrm{C}_{2} \mathrm{H}_{6} \mathrm{CP}$ grade (99.0\%). In each experiment, $c a .20 \mathrm{mg}$ of adsorbent was activated at $373 \mathrm{~K}$ for 10 hours, and further evacuated in situ at $323 \mathrm{~K}$ for 6 hours. The pressure was maintained at 0 mbar without pumping out until mass equilibrium was reached. Then, the pressure was raised at the maximum ramp setting of $2500 \mathrm{mbar} / \mathrm{min}$. Mass data were collected at 1000 mbar until equilibrium was reached.

(a)
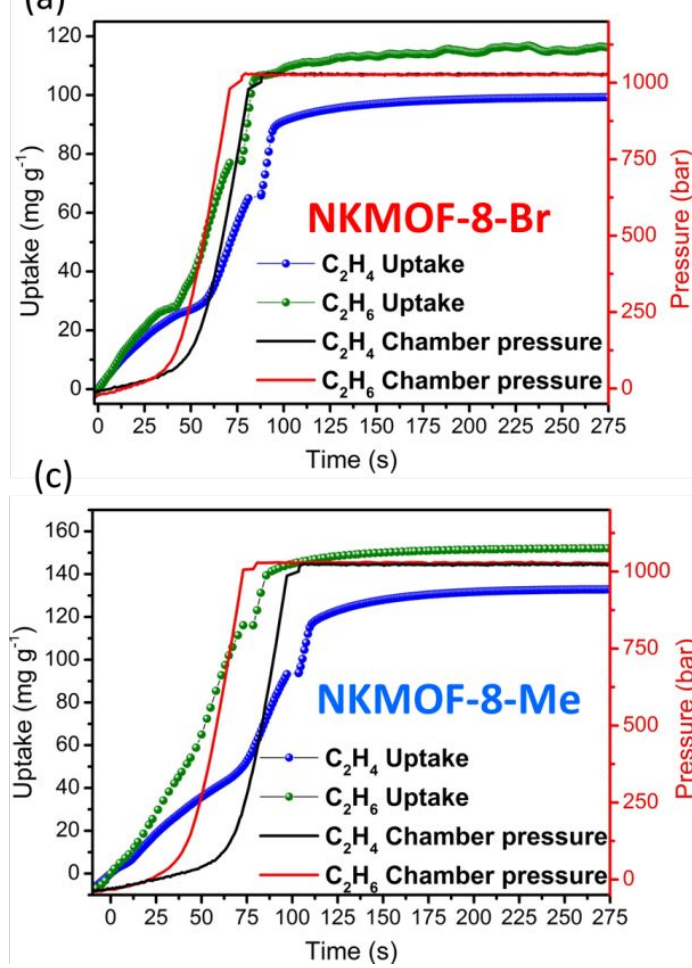

(b)
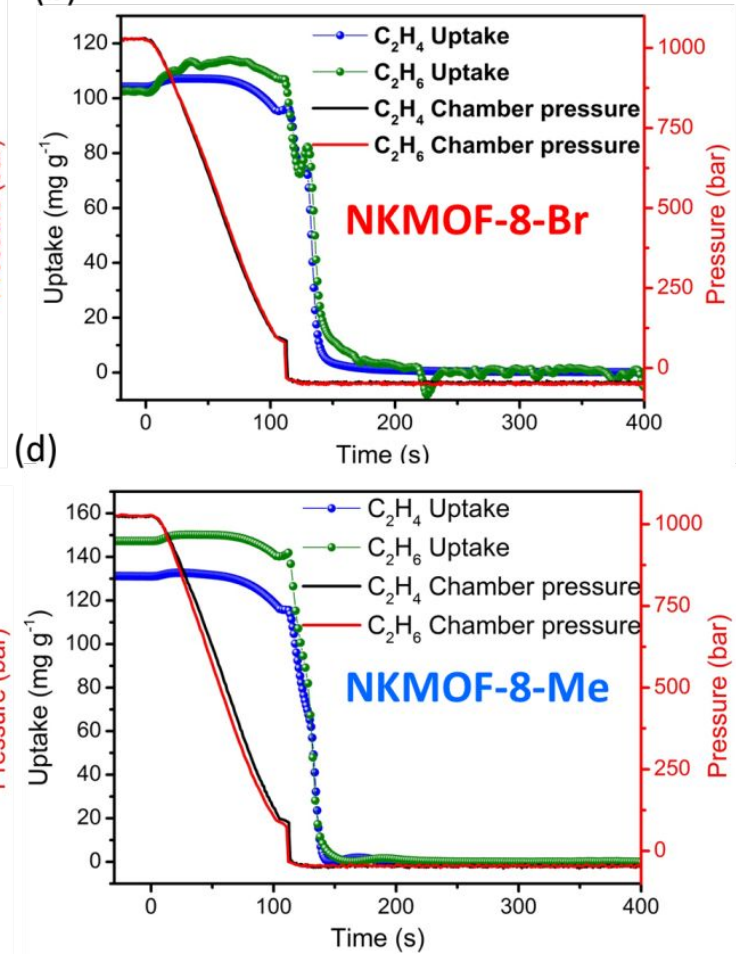

Figure S6. (a, b) kinetic sorption (left) and desorption (right) measurements of $\mathrm{C}_{2} \mathrm{H}_{4}$ and $\mathrm{C}_{2} \mathrm{H}_{6}$ for NKMOF-8-Br. (c, d) kinetic sorption (left) and desorption (right) measurements of $\mathrm{C}_{2} \mathrm{H}_{4}$ and $\mathrm{C}_{2} \mathrm{H}_{6}$ for NKMOF-8-Me.

\section{Isosteric Heats of Adsorption $\left(Q_{\text {st }}\right)$}

The isosteric heats of adsorption of NKMOF-8 were calculated by first fitting the data using the Virial equation:

$$
\ln P=\ln N+\frac{1}{T} \sum_{i=0}^{m} a_{i} N^{i}+\sum_{i=0}^{m} b_{i} N^{i}
$$

Where, $P$ is the pressure (mmHg), $N$ is the amount of gas adsorbed ( $\mathrm{mmol} / \mathrm{g}$ ), $a_{i}$ and $b_{i}$ are virial coefficients, $T$ is the temperature in $\mathrm{K}, m$ and $n$ are the number of coefficients that required to describe the isotherms.

The fitted parameters were then used to determine the $Q_{\text {st }}$ values for a range of uptakes through the following formula: 


$$
Q_{s t}=-R \sum_{i=0}^{m} a_{i} N^{i}
$$

Where, $R$ is the universal gas constant.

(a)

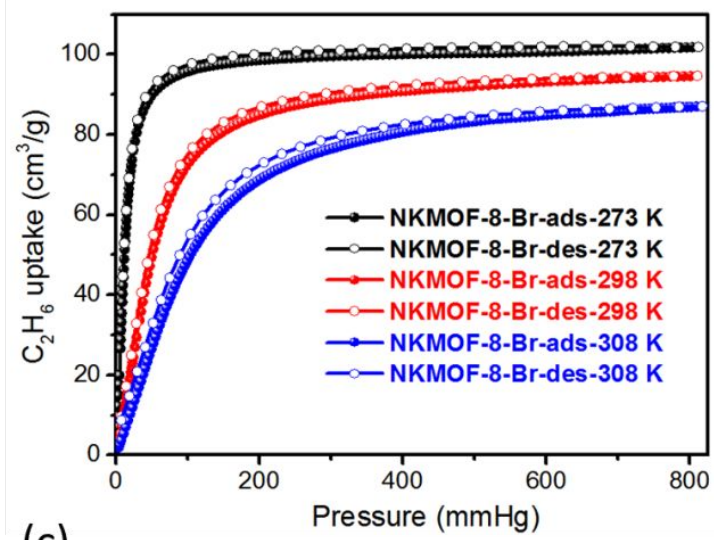

(c)

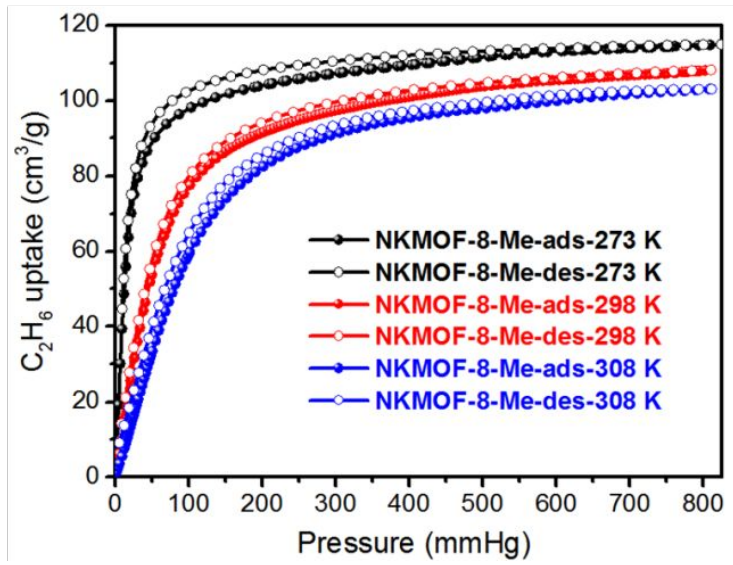

(b)

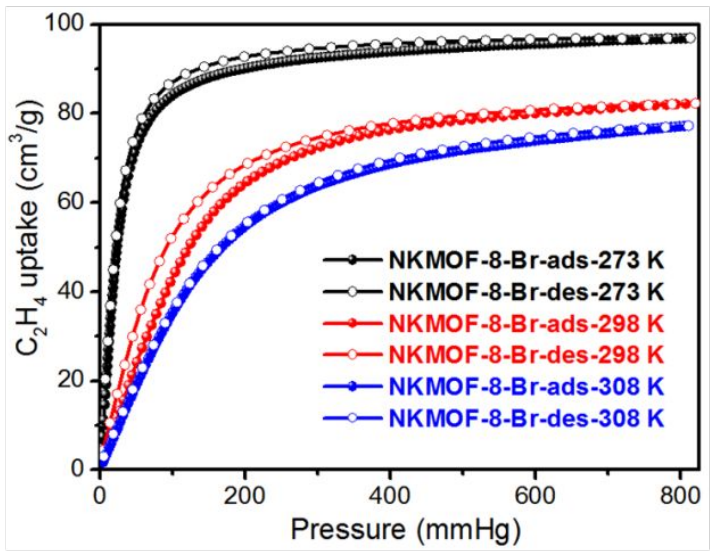

(d)

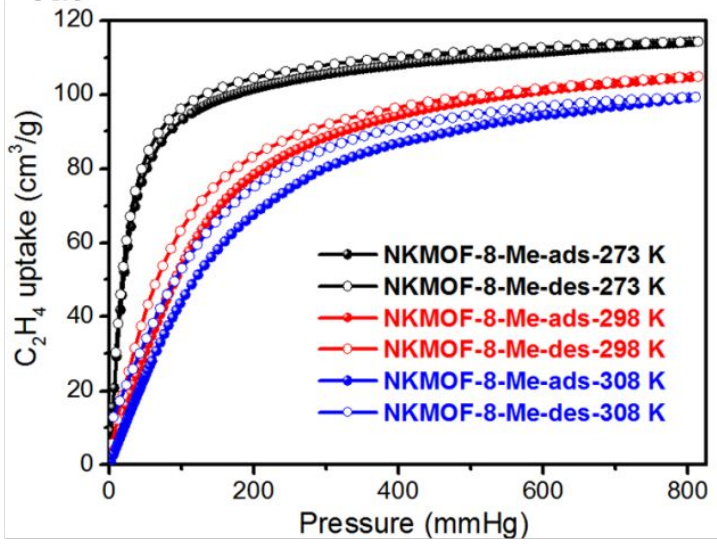

Figure S7. (a, b) Experimental $\mathrm{C}_{2} \mathrm{H}_{6}$ and $\mathrm{C}_{2} \mathrm{H}_{4}$ adsorption isotherms of NKMOF-8-Br at $273 \mathrm{~K}, 298 \mathrm{~K}$ and $308 \mathrm{~K}$ respectively. (b, d) Experimental $\mathrm{C}_{2} \mathrm{H}_{6}$ and $\mathrm{C}_{2} \mathrm{H}_{4}$ adsorption isotherms of NKMOF-8-Me at $273 \mathrm{~K}, 298 \mathrm{~K}$ and $308 \mathrm{~K}$ respectively. 
(a)

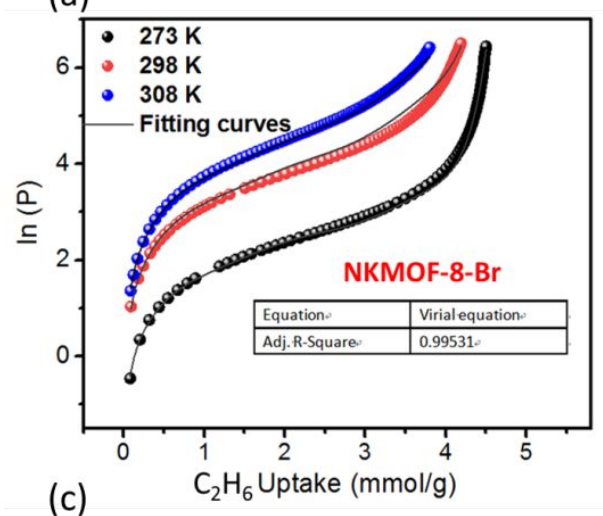

(c)

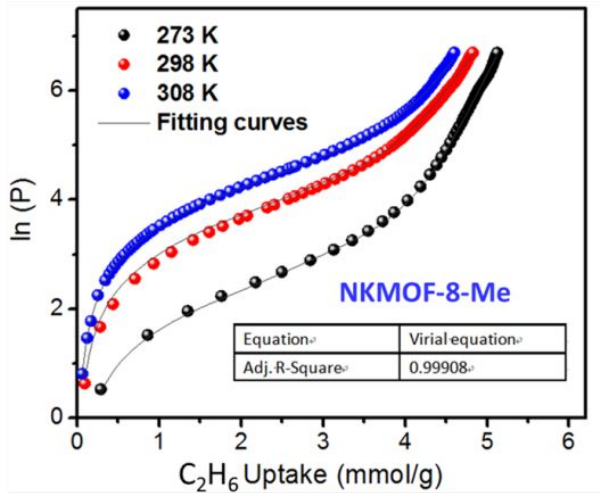

(b)

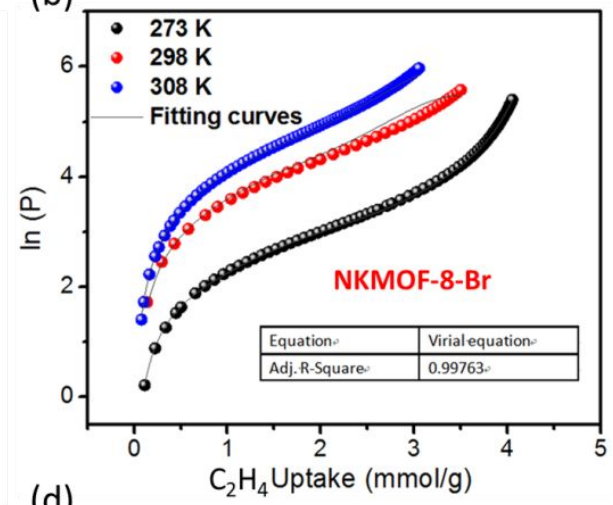

(d)

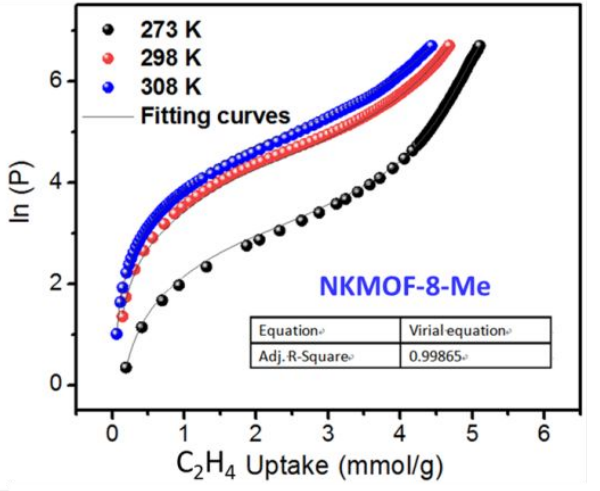

Figure S8. (a, b) Virial equation fitting of $\mathrm{C}_{2} \mathrm{H}_{6}$ and $\mathrm{C}_{2} \mathrm{H}_{4}$ adsorption isotherms of NKMOF-8-Br at $273 \mathrm{~K}, 298 \mathrm{~K}$ and $308 \mathrm{~K}$ respectively. (c, d) Virial equation fitting of $\mathrm{C}_{2} \mathrm{H}_{6}$ and $\mathrm{C}_{2} \mathrm{H}_{4}$ adsorption isotherms of NKMOF-8-Me at $273 \mathrm{~K}, 298 \mathrm{~K}$ and $308 \mathrm{~K}$ respectively.

Table S3. The fitted parameters of the virial equation for NKMOF-8-Br.

\begin{tabular}{|l|l|l|}
\hline \multirow{2}{*}{ Parameter } & \multicolumn{2}{|c|}{ NKMOF-8-Br } \\
\cline { 2 - 3 } & $\mathrm{C}_{2} \mathrm{H}_{6}$ & $\mathrm{C}_{2} \mathrm{H}_{4}$ \\
\hline $\mathrm{a}_{0}$ & -4183.91 & -3866.68 \\
\hline $\mathrm{a}_{1}$ & -1620.47 & -93.57 \\
\hline $\mathrm{a}_{2}$ & 2480.84 & -2046.00 \\
\hline $\mathrm{a}_{3}$ & -3068.07 & 2960.38 \\
\hline $\mathrm{a}_{4}$ & 2476.45 & 1865.25 \\
\hline $\mathrm{a}_{5}$ & -1196.18 & 683.25 \\
\hline $\mathrm{a}_{6}$ & 328.93 & -183.51 \\
\hline $\mathrm{a}_{7}$ & -47.59 & 36.58 \\
\hline $\mathrm{a}_{8}$ & 2.84 & -4.29 \\
\hline $\mathrm{a}_{9}$ & & 0.227 \\
\hline $\mathrm{b}_{0}$ & -17.59 & 16.59 \\
\hline $\mathrm{b}_{1}$ & 3.31 & 0.44 \\
\hline $\mathrm{b}_{2}$ & -2.08 & 5.35 \\
\hline $\mathrm{b}_{3}$ & 0.58 & -6.36 \\
\hline $\mathrm{b}_{4}$ & -0.0257 & 2.65 \\
\hline $\mathrm{b}_{5}$ & & -0.35 \\
\hline Adj. R-Square & 0.99531 & 0.99763 \\
\hline
\end{tabular}


Table S4. The fitted parameters of the virial equation for NKMOF-8-Me.

\begin{tabular}{|l|l|l|}
\hline \multirow{2}{*}{ Parameter } & \multicolumn{2}{|c|}{ NKMOF-8-Me } \\
\cline { 2 - 3 } & $\mathrm{C}_{2} \mathrm{H}_{6}$ & $\mathrm{C}_{2} \mathrm{H}_{4}$ \\
\hline $\mathrm{a}_{0}$ & -4705.06 & -4832.24 \\
\hline $\mathrm{a}_{1}$ & 1079.97 & 2544.58 \\
\hline $\mathrm{a}_{2}$ & -2157.19 & -3508.83 \\
\hline $\mathrm{a}_{3}$ & 2203.59 & 2527.67 \\
\hline $\mathrm{a}_{4}$ & -1443.63 & -1198.17 \\
\hline $\mathrm{a}_{5}$ & 650.38 & 406.08 \\
\hline $\mathrm{a}_{6}$ & -191.84 & -93.21 \\
\hline $\mathrm{a}_{7}$ & 34.21 & 12.75 \\
\hline $\mathrm{a}_{8}$ & -3.29 & -0.86 \\
\hline $\mathrm{a}_{9}$ & 0.13 & 0.019 \\
\hline $\mathrm{b}_{0}$ & 18.79 & 19.44 \\
\hline $\mathrm{b}_{1}$ & -2.76 & -7.44 \\
\hline $\mathrm{b}_{2}$ & 4.03 & 8.72 \\
\hline $\mathrm{b}_{3}$ & -2.39 & -4.27 \\
\hline $\mathrm{b}_{4}$ & 0.60 & 0.94 \\
\hline $\mathrm{b}_{5}$ & -0.054 & -0.077 \\
\hline Adj. R-Square & 0.99908 & 0.99865 \\
\hline
\end{tabular}


(a)

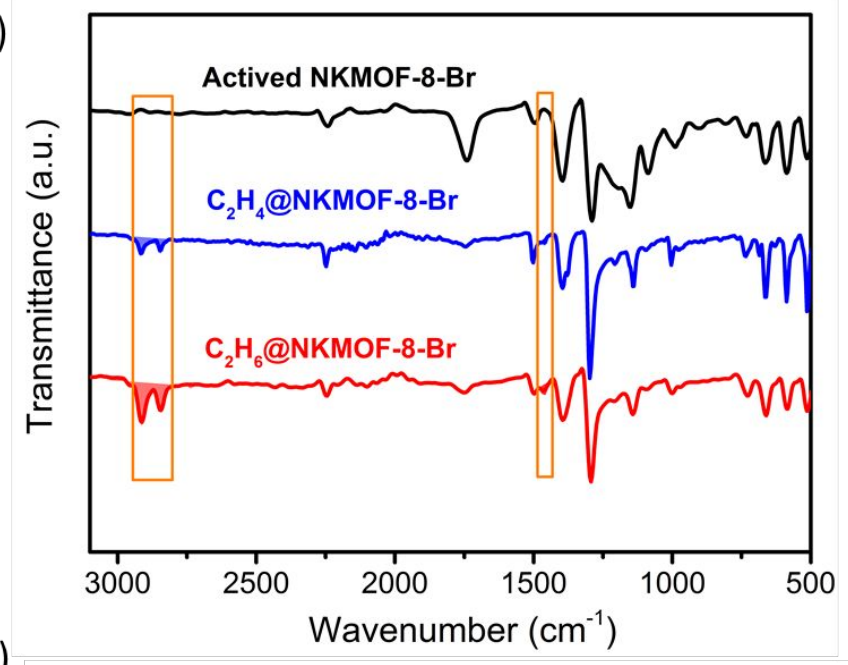

(b)

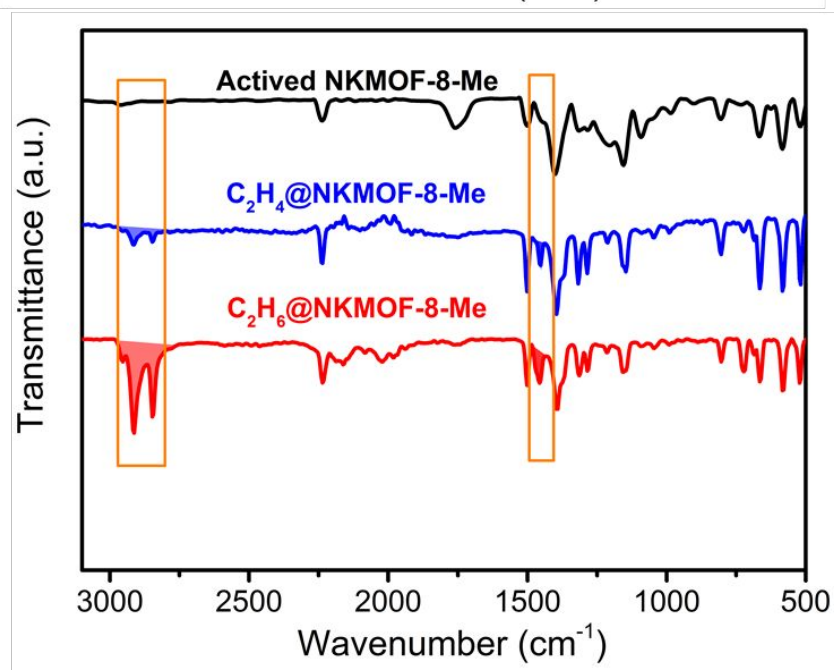

Figure S9. FT-IR of NKMOF-8-Br and NKMOF-8-Me absorbed $\mathrm{C}_{2} \mathrm{H}_{4}, \mathrm{C}_{2} \mathrm{H}_{6}$ at room temperature (shaded areas are infrared absorption peaks of $\mathrm{C}_{2} \mathrm{H}_{4}$ and $\mathrm{C}_{2} \mathrm{H}_{6}$ ).

\section{Computational Results and Details}

The grand canonical Monte Carlo (GCMC) simulation was performed using Sorption Module in Materials Studio to simulate $\mathrm{C}_{2} \mathrm{H}_{4}$ and $\mathrm{C}_{2} \mathrm{H}_{6}$ adsorption in NKMOF-8. The simulation box of the GCMC run was constructed by $3 \times 3 \times 3$ supercell of the respective MOFs, and a cut-off radius of 12.6864 and $13.3342 \AA$ was used for the simulations, which corresponded to half of the shortest system cell dimension length. The Lennard-Jones (LJ) parameters for frameworks were obtained from Dreiding force field ${ }^{\mathrm{S} 16}$, and if not available, from the universal force field (UFF) ${ }^{\mathrm{S} 17}$. The LJ parameters for gas molecules were taken from literature ${ }^{\mathrm{S} 18-19}$. The simulations started with a $5,000,000$-cycle of equilibration steps and were followed by 5,000,000-cycle production steps. According to the simulations, the simulated results of $\mathrm{C}_{2} \mathrm{H}_{4}$ and $\mathrm{C}_{2} \mathrm{H}_{6}$ uptakes of NKCOF-8-Br were $(\sim 83, \sim 81) \mathrm{cm}^{3} \mathrm{~g}^{-1}$ NKCOF-8-Me $(\sim 106, \sim 96) \mathrm{cm}^{3} \mathrm{~g}^{-1}$, respectively, at $298 \mathrm{~K}$ and 1 bar, validating the use of these force fields.

The Density functional theory (DFT) calculations were carried out to determine the binding energy for $\mathrm{C}_{2} \mathrm{H}_{4}$ and $\mathrm{C}_{2} \mathrm{H}_{6}$ in NKMOF-8 by using DMol3 program in the Materials Studio. The 
Lowest energy configurations obtained from GCMC simulations were selected as the initial positions of gas molecules, the position of gas molecules was firstly optimized, followed by a full structural relaxation of all atoms and lattice parameters of the system. Perdew-Burke-Ernzerhof ( PBE ) functional with generalized gradient approximation (GGA) were used for our calculations. All electron core treatment double numerical plus polarization (DNP) basis set were selected. Grimme method was used for the dispersion-energy corrections.

The static binding energy (at $\mathrm{T}=0 \mathrm{~K}$ ) was calculated by the following: $\Delta \mathrm{E}=\mathrm{E}(\mathrm{MOF}+$ gas molecule $)-\mathrm{E}(\mathrm{MOF})-\mathrm{E}($ gas molecule $)$

Table S5. The calculated intermolecular interaction energy between gases and NKMOF-8-Br and -Me

\begin{tabular}{|c|c|c|}
\hline MOF & Adsorbate & $\Delta \mathrm{E}\left(\mathrm{kJ} \cdot \mathrm{mol}^{-1}\right)$ \\
\hline \multirow{2}{*}{ NKMOF-8-Br } & $\mathrm{C}_{2} \mathrm{H}_{4}$ & -51.8 \\
\cline { 2 - 3 } & $\mathrm{C}_{2} \mathrm{H}_{6}$ & -57.2 \\
\hline \multirow{2}{*}{ NKMOF-8-Me } & $\mathrm{C}_{2} \mathrm{H}_{4}$ & -49.2 \\
\cline { 2 - 3 } & $\mathrm{C}_{2} \mathrm{H}_{6}$ & -52.7 \\
\hline
\end{tabular}
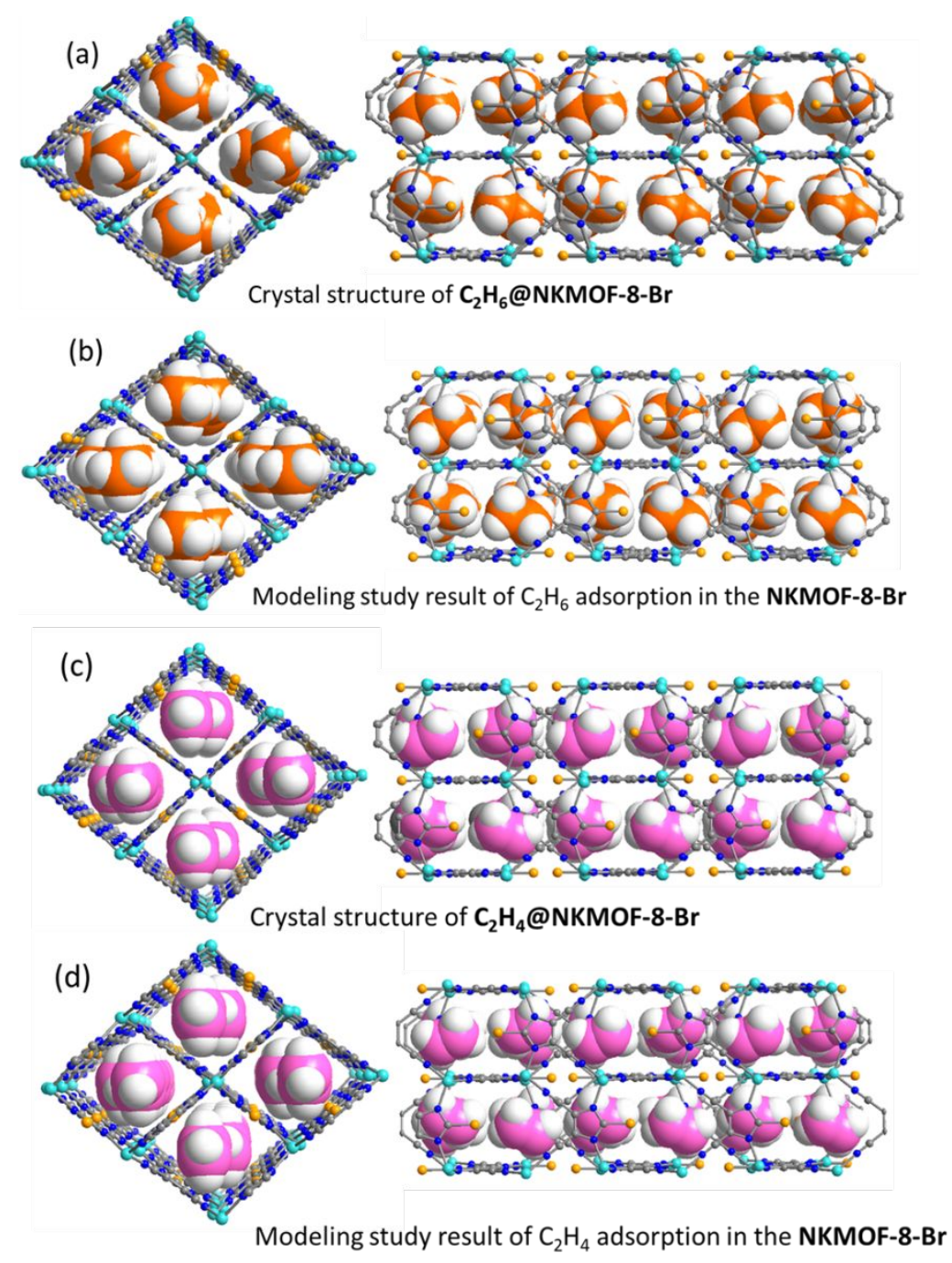

Figure S10. (a, c) The crystal structures of $\mathrm{C}_{2} \mathrm{H}_{6} @ N K M O F-8-B r$ and $\mathrm{C}_{2} \mathbf{H}_{4} @ N K M O F-8-B r$. (b, d) Modeling study results of $\mathrm{C}_{2} \mathrm{H}_{6}$ and $\mathrm{C}_{2} \mathrm{H}_{4}$ adsorption in the NKMOF-8-Br. 

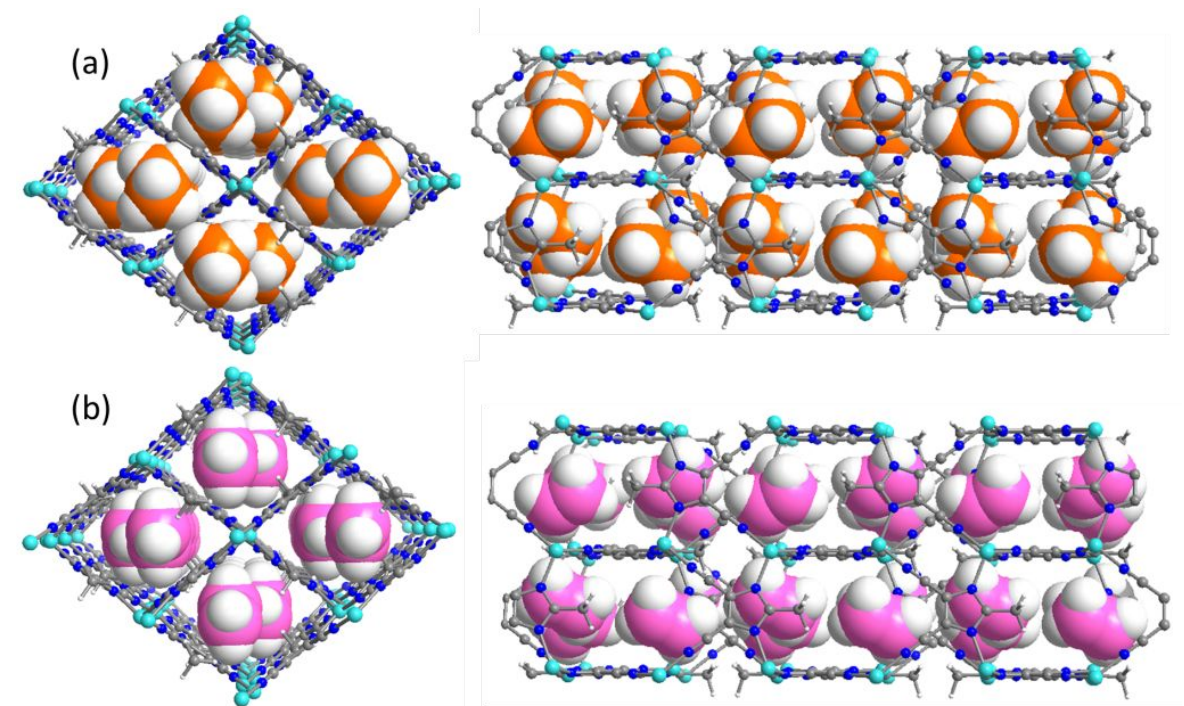

Figure S11. Modeling study results of $\mathrm{C}_{2} \mathrm{H}_{6}$ and $\mathrm{C}_{2} \mathrm{H}_{4}$ adsorption in the NKMOF-8-Me.

(a)

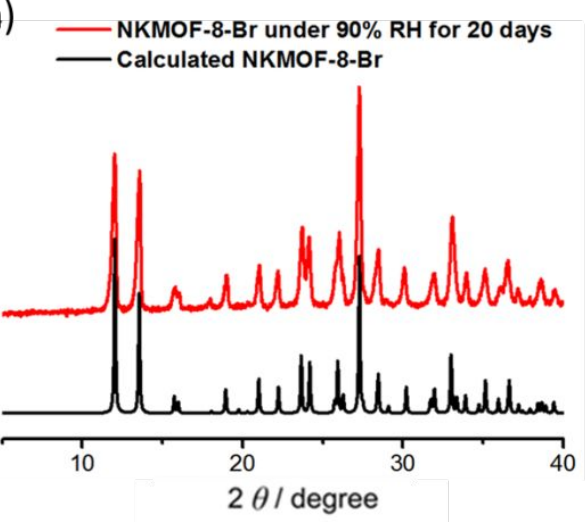

(b)

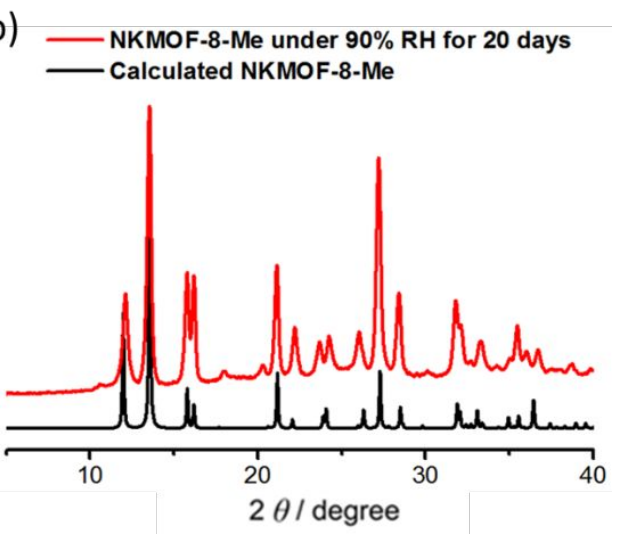

Figure S12. PXRD patterns for NKMOF-8-Br and -Me treated with 90\% RH for 20 days. 
(a)

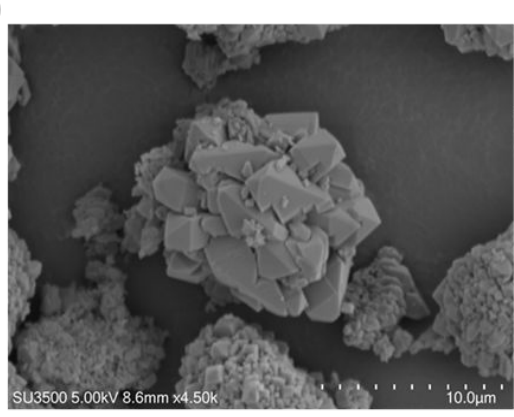

(c)

C) NKMOF-8-Br after water adsorption test

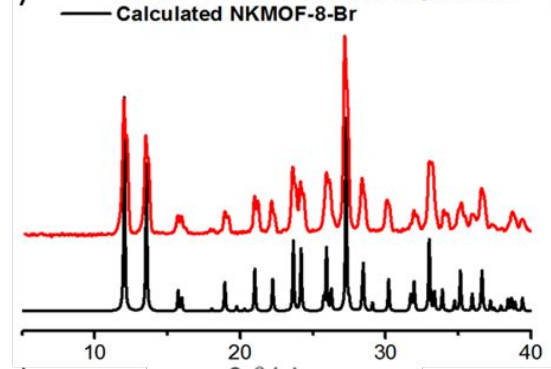

(e)

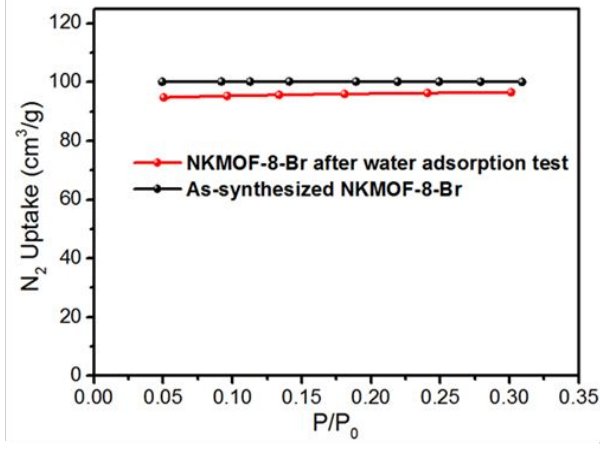

(b)

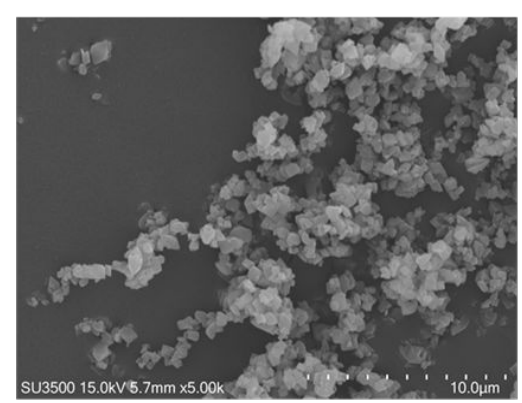

(d)

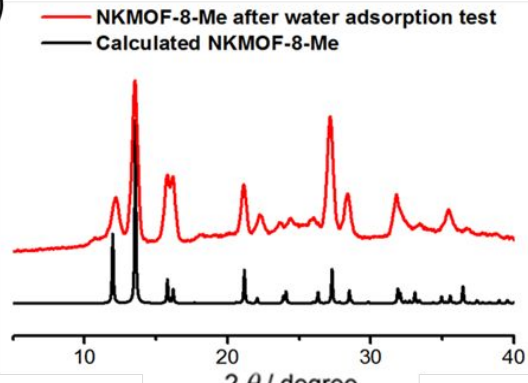

(f)

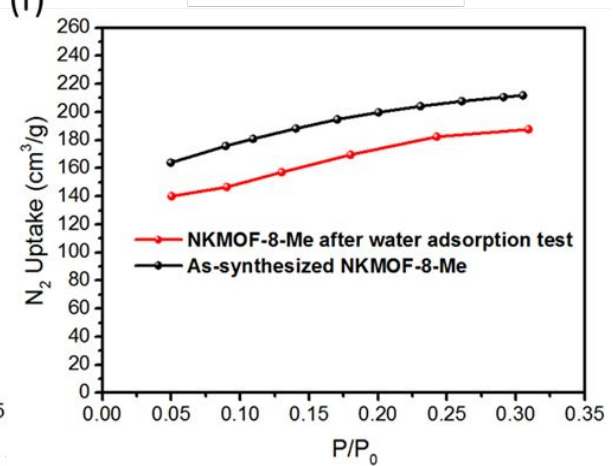

Figure S13. SEM, PXRD and BET data after water vapor sorption test for NKMOF-8-Br and-Me.

\section{Dynamic vapor sorption of water}

Dynamic water vapor sorption studies were performed on ca. 10-20 mg sample using dynamic vapor sorption system (Surface Measurement Systems, DVS Adventure), which gravimetrically measures the uptake and loss of vapor using air as a carrier gas. Pure water was used as the adsorbate for these measurements, and temperature was maintained at $298 \mathrm{~K}$ by enclosing the system in a temperature-controlled incubator. The mass of the sample was determined by comparison to an empty reference pan and recorded by a high-resolution microbalance with a precision of $0.1 \mu \mathrm{g}$. Sorption isotherms were measured from 0 to $95 \%$ RH step-wise with a convergence equilibrium criterion $\mathrm{dm} / \mathrm{dt}$ $=0.05 \% / \mathrm{min}$. The minimum and maximum equilibration times for each step were 10 and $360 \mathrm{~min}$. 


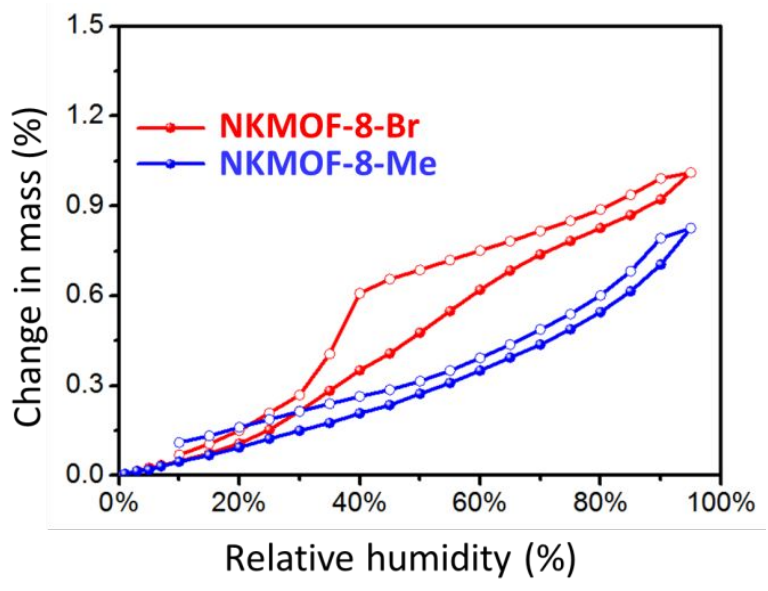

Figure S14. Dynamic water vapor sorption (DVS) plots for NKMOF-8-Br and-Me.

\section{Ideal Adsorbed Solution Theory (IAST) Selectivity}

The $\mathrm{C}_{2} \mathrm{H}_{6} / \mathrm{C}_{2} \mathrm{H}_{4}(1: 1, \mathrm{v} / \mathrm{v})$ selectivities in NKMOF-8-Br and NKMOF-8-Me at $298 \mathrm{~K}$ were calculated using ideal adsorbed solution theory (IAST). ${ }^{20}$ First, the single-component adsorption isotherms for $\mathrm{C}_{2} \mathrm{H}_{4}$ and $\mathrm{C}_{2} \mathrm{H}_{6}$ at $298 \mathrm{~K}$ for both MOFs were fitted to the dual-site Langmuir-Freundlich equation (DSLF): ${ }^{21}$

$$
n=\frac{n_{m 1} b_{1} P^{\left(\frac{1}{t_{1}}\right)}}{1+b_{1} P^{\left(\frac{1}{t_{1}}\right)}}+\frac{n_{m 2} b_{2} P^{\left(\frac{1}{t_{2}}\right)}}{1+b_{2} P^{\left(\frac{1}{t_{2}}\right)}}
$$

where $n$ is the uptake (in mmol $\mathrm{g}^{-1}$ ), $P$ is the pressure (in $\mathrm{kPa}$ ), $n_{m 1}$ and $n_{m 2}$ are the saturation uptakes (in mmol g-1) for sites 1 and 2, $b_{1}$ and $b_{2}$ are the affinity coefficients (in $\mathrm{kPa}^{-1 / t_{1}}$ and $\mathrm{kPa}^{-1 / t_{2}}$, respectively) for sites 1 and 2 , and $t_{1}$ and $t_{2}$ represent the deviations from the ideal homogeneous surface (unitless) for sites 1 and 2. The parameters that were obtained from the fitting of the $\mathrm{C}_{2} \mathrm{H}_{4}$ and $\mathrm{C}_{2} \mathrm{H}_{6}$ adsorption isotherms at $298 \mathrm{~K}$ for NKMOF-8-Br and NKMOF-8-Me are found in Table S1. All isotherms were fitted with $\mathrm{R}^{2}>0.9999$.

The spreading pressure $(\pi)$ for adsorbates $i$ and $j$ can be calculated using the following equations:

$$
\begin{aligned}
& \frac{\pi_{i}^{\circ} A}{R T}=\int_{0}^{P_{i}^{\circ}} \frac{n_{i}}{P} d P \\
& \frac{\pi_{j}^{\circ} A}{R T}=\int_{0}^{P_{j}^{\circ}} \frac{n_{j}}{P} d P
\end{aligned}
$$

where $A$ represents the specific surface area (assumed to be the same for all adsorbates), $R$ is the ideal gas constant, $T$ is the temperature, and $P^{\circ}{ }_{i}$ and $P_{j}^{\circ}$ are the equilibrium gas phase pressures corresponding to the solution temperature and solution spreading pressure for the adsorption of pure components $i$ and $j$, respectively. Moreover, the following equations hold true for a two-component mixture according to IAST: 19

$$
\pi_{i}^{\circ}=\pi_{j}^{\circ}
$$




$$
\begin{aligned}
& P y_{i}=P_{i}^{\circ} x_{i} \\
& P y_{j}=P_{j}^{\circ} x_{i} \\
& x_{i}+x_{j}=1 \\
& y_{i}+y_{j}=1
\end{aligned}
$$

Here, $x_{i}$ and $x_{j}$ are the mole fractions of components $i$ and $j$, respectively, in the adsorbed phase, and $y_{i}$ and $y_{j}$ are the mole fractions of components $i$ and $j$, respectively, in the gas phase. The previous seven equations are seven independent equations with nine unknowns. In order to solve for all of the unknowns, two quantities must be specified, particularly $P$ and $y_{i}$. Utilization of the above equations yields the following equilibrium expression for adsorbates $i$ and $j$ :

$$
\int_{0}^{\frac{P y_{i}}{x_{i}}} \frac{n_{i}}{P} d P=\int_{0}^{\frac{P\left(1-y_{j}\right)}{\left(1-x_{i}\right)}} \frac{n_{j}}{P} d P
$$

This equation was solved for $x_{i}$ using numerical analysis (e.g., the Newton-Raphson method) ${ }^{22}$ for a range of pressures at a specified $y_{i}$ value. Finally, the selectivity for adsorbate $i$ relative to adsorbate $j$ was calculated using the following:

$$
S_{i / j}=\frac{x_{i}}{x_{j}} \frac{y_{j}}{y_{i}}
$$

Table S6: The fitted parameters for the DSLF equation for the $\mathrm{C}_{2} \mathrm{H}_{4}$ and $\mathrm{C}_{2} \mathrm{H}_{6}$ adsorption isotherms for NKMOF-8-Br and NKMOF-8-Me at $298 \mathrm{~K}$. The $\mathrm{R}^{2}$ values are also provided.

\begin{tabular}{|c|c|c|c|}
\hline Adsorbate & Parameter & NKMOF-8-Br & NKMOF-8-Me \\
\hline \multirow{5}{*}{$\mathrm{C}_{2} \mathrm{H}_{4}$} & $n_{m 1}\left(\mathrm{mmol} \mathrm{g}^{-1}\right)$ & 3.01755470 & 4.57423121 \\
\cline { 2 - 4 } & $b_{1}\left(\mathrm{kPa}^{-1 / t_{1}}\right)$ & 0.05225007 & 0.05477758 \\
\cline { 2 - 4 } & $t_{1}$ & 0.85150043 & 0.94725161 \\
\cline { 2 - 4 } & $n_{m 2}\left(\mathrm{mmol} \mathrm{g}^{-1}\right)$ & 0.86910517 & 0.63248667 \\
\cline { 2 - 4 } & $b_{2}\left(\mathrm{kPa}^{-1 / t_{2}}\right)$ & 0.00035837 & 0.00006861 \\
\cline { 2 - 4 } & $t_{2}$ & 0.34266659 & 0.27202029 \\
\cline { 2 - 4 } & $\mathrm{R}^{2}$ & 0.99998579 & 0.99999285 \\
\hline \multirow{5}{*}{$\mathrm{C}_{2} \mathrm{H}_{6}$} & $n_{m 1}\left(\mathrm{mmol} \mathrm{g}^{-1}\right)$ & 3.01709322 & 2.88099209 \\
\cline { 2 - 4 } & $b_{1}\left(\mathrm{kPa}^{-1 / t_{1}}\right)$ & 0.02855958 & 0.04416114 \\
\cline { 2 - 4 } & $t_{1}$ & 0.50774594 & 0.56230498 \\
\cline { 2 - 4 } & $n_{m 2}\left(\mathrm{mmol} \mathrm{g}^{-1}\right)$ & 1.47741898 & 2.66519844 \\
\cline { 2 - 4 } & $b_{2}\left(\mathrm{kPa}^{-1 / t_{2}}\right)$ & 0.16144985 & 0.11824632 \\
\cline { 2 - 4 } & $t_{2}$ & 1.39930060 & 1.48395805 \\
\cline { 2 - 4 } & $\mathrm{R}^{2}$ & 0.99997703 & 0.99993429 \\
\hline
\end{tabular}


(a)

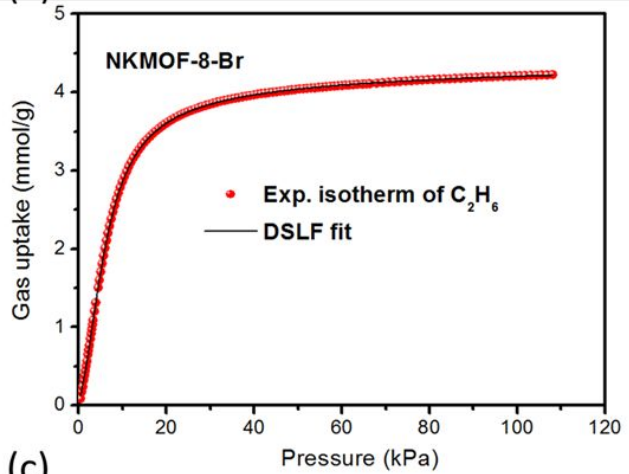

(c)

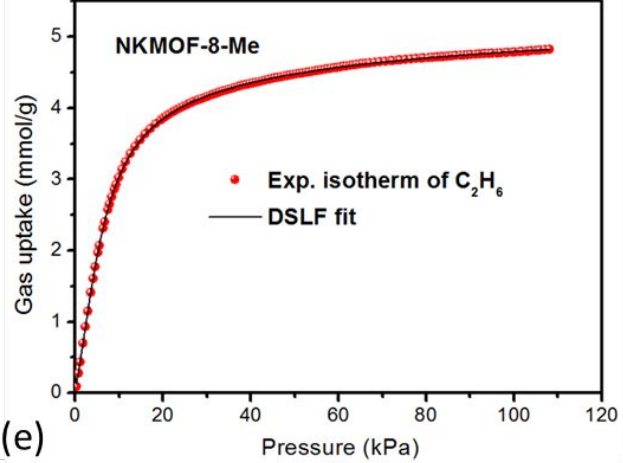

(e)

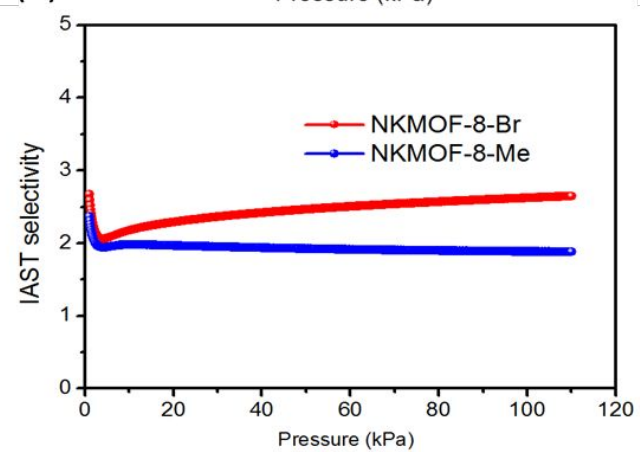

(b)

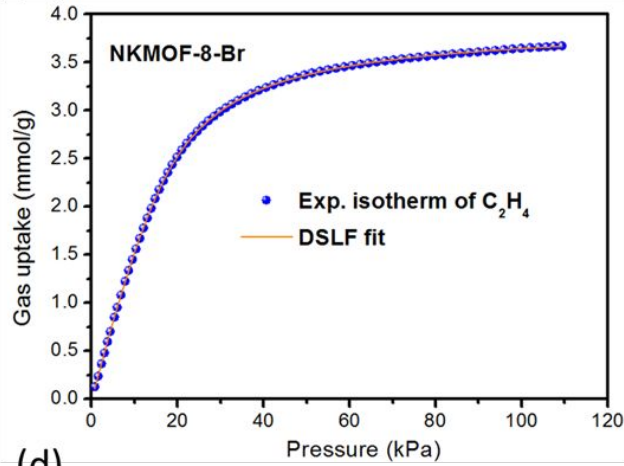

(d)

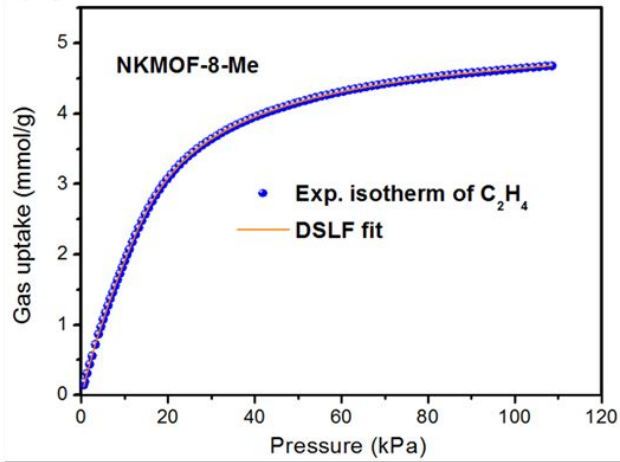

Figure S15. (a, b) DSLF fit of the $\mathrm{C}_{2} \mathrm{H}_{6}$ adsorption isotherm (left) and $\mathrm{C}_{2} \mathrm{H}_{4}$ adsorption isotherm (right) of NKMOF-8-Br at $298 \mathrm{~K}$. (c, d) DSLF fit of the $\mathrm{C}_{2} \mathrm{H}_{6}$ adsorption isotherm (left) and $\mathrm{C}_{2} \mathrm{H}_{4}$ adsorption isotherm (right) of NKMOF-8-Me at $298 \mathrm{~K}$. (e) IAST selectivities of $\mathrm{C}_{2} \mathrm{H}_{6} / \mathrm{C}_{2} \mathrm{H}_{4}(1: 1, \mathrm{v} / \mathrm{v})$ mixtures for NKMOF-8-Br and -Me at $298 \mathrm{~K}$.

\section{Column Breakthrough Experiments}

The breakthrough separation experiments were conducted in a home-built breakthrough apparatus under ambient conditions $(298 \mathrm{~K}, 1 \mathrm{~atm})$. In a typical breakthrough experiment for $\mathrm{C}_{2} \mathrm{H}_{6} / \mathrm{C}_{2} \mathrm{H}_{4}(1: 1$, $\mathrm{v} / \mathrm{v})$ gas mixtures. $23.23 \mathrm{mmol}$ samples, NKMOF-8-Br (6.07 g), NKMOF-8-Me (4.60 g), $\mathbf{C u}(\mathbf{Q c})_{2}(6.07 \mathrm{~g})$, PCN-250 (6.07 g) MIL-142A (6.07g), MCIF-1 (4.23 g), were packed in a stainless steel column (6 mm inner diameter, $500 \mathrm{~mm}$ length) and purged with $\mathrm{He}$ flow (20 $\mathrm{mL} / \mathrm{min}$ ) for 10 hours at $100{ }^{\circ} \mathrm{C}$ for the activation process. Then keeping gas mixture flow, $\mathrm{C}_{2} \mathrm{H}_{6} / \mathrm{C}_{2} \mathrm{H}_{4}(1: 1, \mathrm{v} / \mathrm{v})$ or $\mathrm{C}_{2} \mathrm{H}_{6} / \mathrm{C}_{2} \mathrm{H}_{4}(1: 9, \mathrm{v} / \mathrm{v})$ with $\mathrm{He}$ as the carrier gas $(70 \%$, vol\%) was added at a total flow $3 \mathrm{~mL} / \mathrm{min}$ at room temperature. Outlet gas from the sample holder was monitored by using as chromatography (Nexis GC-2030, SHIMADZU) continuously until the breakthrough was completed. After the breakthrough experiment, the adsorbent was regenerated in-situ by heating 
for 5 hours at $100^{\circ} \mathrm{C}$ to finish five cycles of the experimental breakthrough test.

Additionally, breakthrough experiments for $\mathrm{C}_{2} \mathrm{H}_{6} / \mathrm{C}_{2} \mathrm{H}_{4}(1: 1, \mathrm{v} / \mathrm{v})$ gas mixtures without $\mathrm{He}$ as the carrier gas were also conducted. NKMOF-8-Br $(6.07 \mathrm{~g})$ or NKMOF-8-Me (4.60 g) were packed in a stainless steel column $(6 \mathrm{~mm}$ inner diameter, $500 \mathrm{~mm}$ length) and purged with $\mathrm{He}$ flow $(20 \mathrm{~mL} / \mathrm{min})$ for 10 hours at $100{ }^{\circ} \mathrm{C}$ for the activation process. After cooling to target temperature $(298 \mathrm{~K})$, turn off $\mathrm{He}$ gas and let $\mathrm{C}_{2} \mathrm{H}_{6} / \mathrm{C}_{2} \mathrm{H}_{4}(1: 1, \mathrm{v} / \mathrm{v})$ mixture was fed to the column at a flow rate of $0.7 \mathrm{~mL} / \mathrm{min}$. Outlet gas was online analyzed by a gas chromatograph (Nexis GC-2030, SHIMADZU).
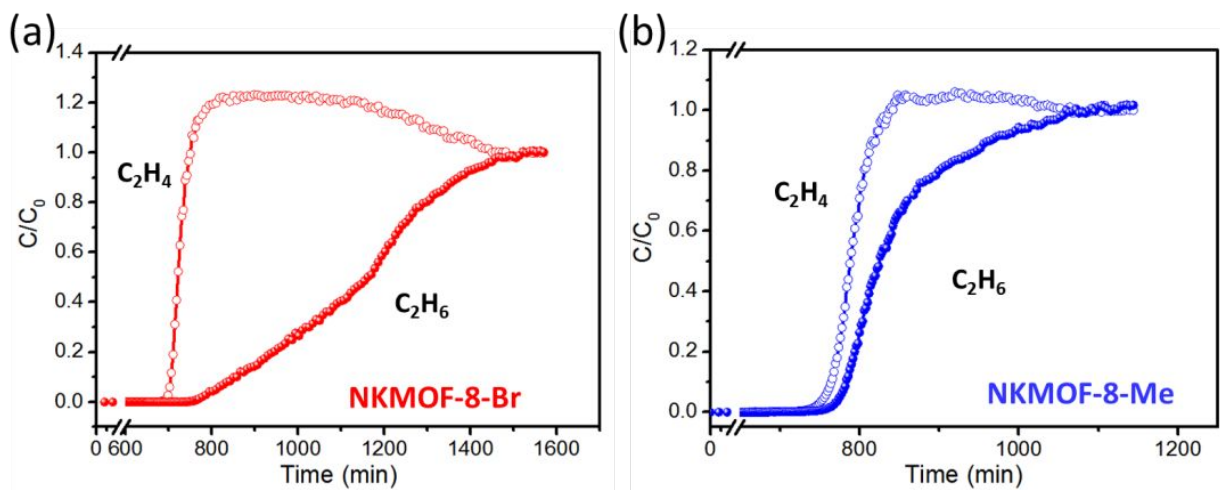

Figure S16. (a, b) Experimental breakthrough curves of $\mathrm{C}_{2} \mathrm{H}_{6} / \mathrm{C}_{2} \mathrm{H}_{4}(1: 1, \mathrm{v} / \mathrm{v})$ mixture without He gas as the carrier gas for NKMOF-8-Br and NKMOF-8-Me under a $0.7 \mathrm{~mL} / \mathrm{min}$ flow at $298 \mathrm{~K}$ and 1 bar.
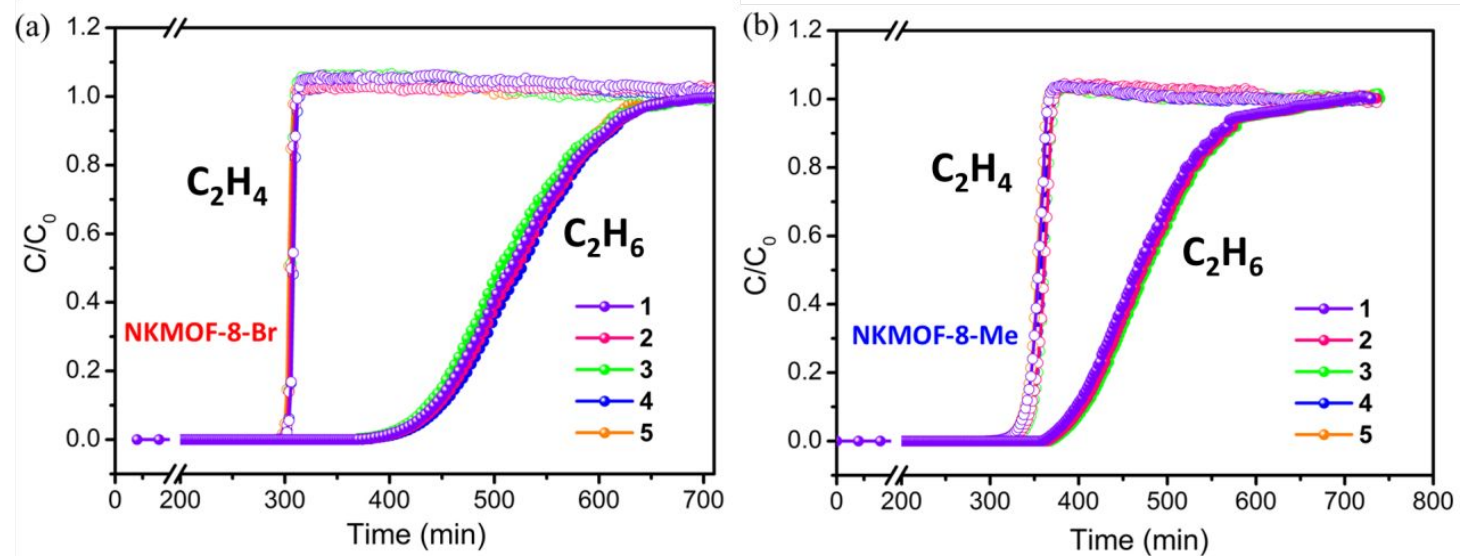

Figure S17. (a, b) Five cycles of experimental breakthrough curves of $\mathrm{C}_{2} \mathrm{H}_{6} / \mathrm{C}_{2} \mathrm{H}_{4}(1: 9, \mathrm{v} / \mathrm{v})$ mixture with $\mathrm{He}$ as the carrier gas (70\%, vol\%) for NKMOF-8-Br and NKMOF-8-Me at $298 \mathrm{~K}$ and 1 bar. The total flow rate was $3 \mathrm{~mL} / \mathrm{min}$. 
(a)

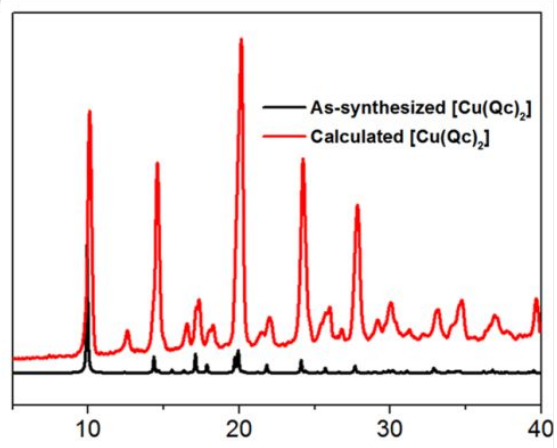

(c)

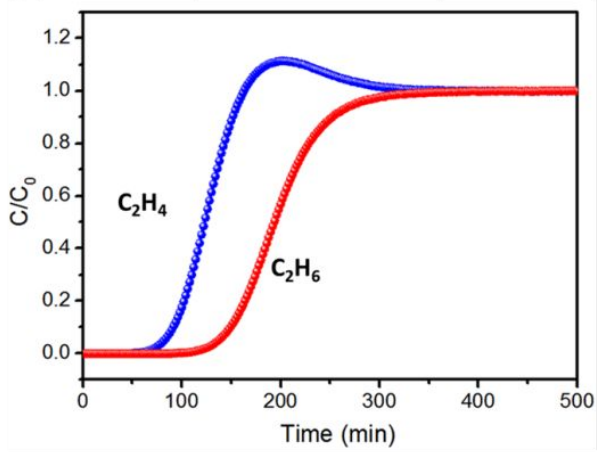

(b)

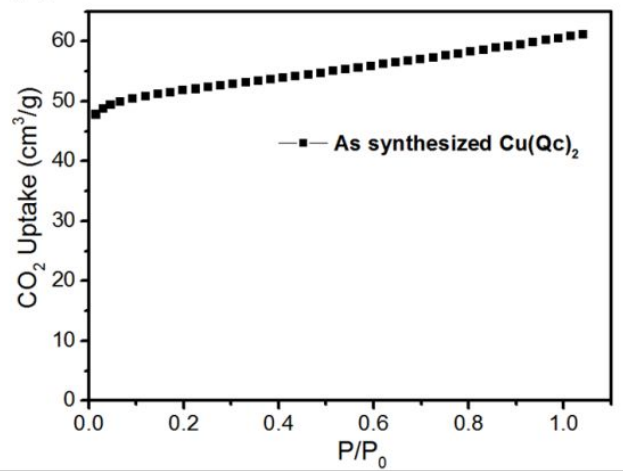

Figure S18. (a) PXRD patterns of $\mathbf{C u}(\mathbf{Q c})_{2}$. (b) $\mathrm{CO}_{2}$ adsorption isotherm of $\mathbf{C u}(\mathbf{Q c})_{2}$ at $195 \mathrm{~K}$. (c) Experimental breakthrough curves of $\mathrm{C}_{2} \mathrm{H}_{6} / \mathrm{C}_{2} \mathrm{H}_{4}(1: 1, \mathrm{v} / \mathrm{v})$ mixture with $\mathrm{He}$ as the carrier gas $(70 \%$, vol\%) for $\mathbf{C u}(\mathbf{Q c})_{2}$ at $298 \mathrm{~K}$ and 1 bar. The total flow rate was $3 \mathrm{~mL} / \mathrm{min}$.

(a)



(c)

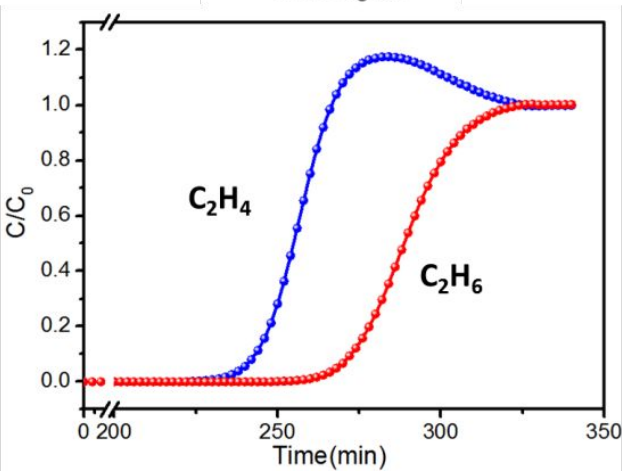

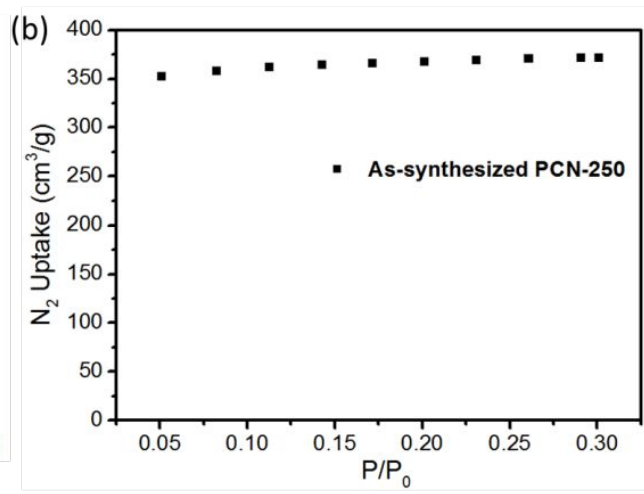

Figure S19. (a) PXRD patterns of PCN-250. (b) BET of PCN-250. (c) Experimental breakthrough curves of $\mathrm{C}_{2} \mathrm{H}_{6} / \mathrm{C}_{2} \mathrm{H}_{4}(1: 1, \mathrm{v} / \mathrm{v})$ mixture with $\mathrm{He}$ as the carrier gas $(70 \%$, vol\%) for PCN-250 at $298 \mathrm{~K}$ and 1 bar. The total flow rate was $3 \mathrm{~mL} / \mathrm{min}$. 

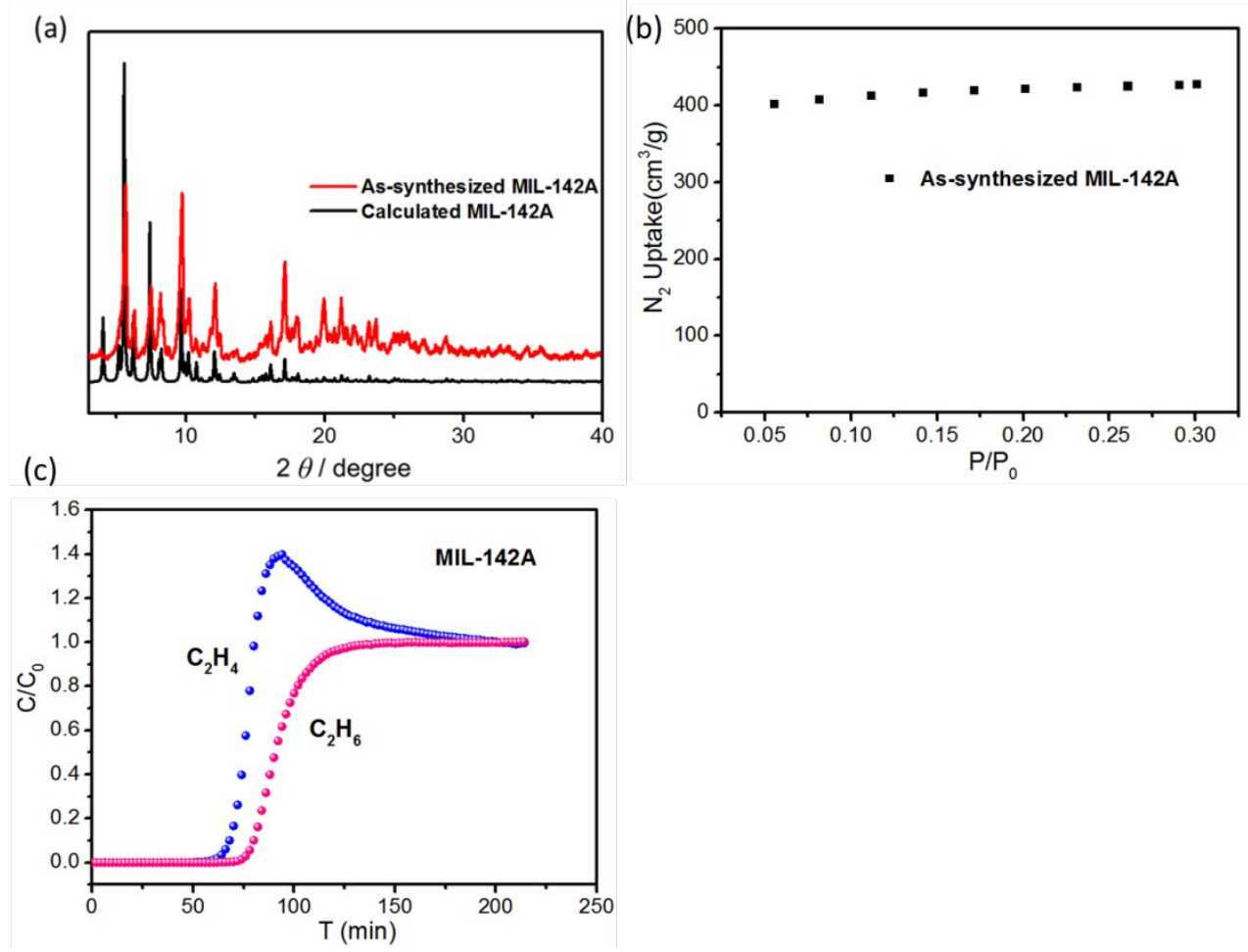

Figure S20. (a) PXRD patterns of MIL-142A. (b) BET of MIL-142A. (c) Experimental breakthrough curves of $\mathrm{C}_{2} \mathrm{H}_{6} / \mathrm{C}_{2} \mathrm{H}_{4}(1: 1, \mathrm{v} / \mathrm{v})$ mixture with $\mathrm{He}$ as the carrier gas $(70 \%$, vol\%) for MIL-142A at $298 \mathrm{~K}$ and 1 bar. The total flow rate was $3 \mathrm{~mL} / \mathrm{min}$.

(a)

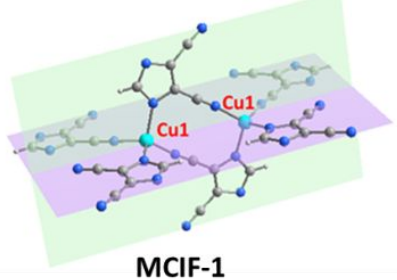

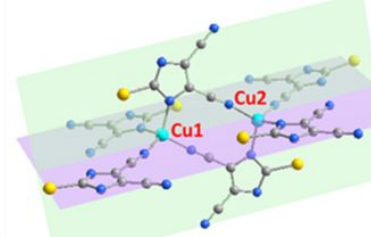

NKMOF-8-Br

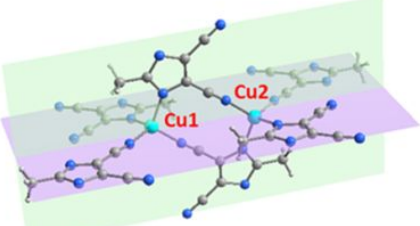

NKMOF-8-Me

(b)

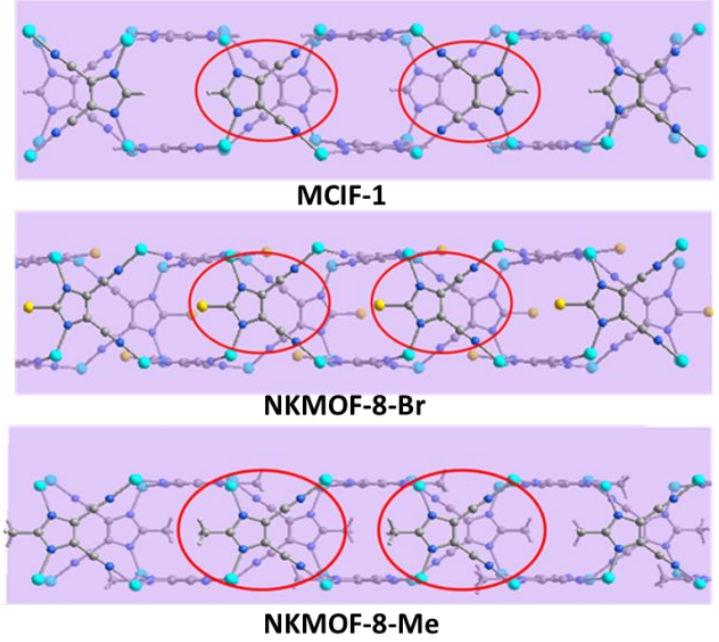

Figure S21. (a) Coordination environment of $\mathrm{Cu}(\mathrm{I})$ atoms in MCIF-1 (left), NKMOF-8-Br (middle) and NKMOF-8-Me (right). (b) Head-to-head and tail-to-tail connection styles in MCIF-1(top), head-to-tail connection style in NKMOF-8-Br (middle) and NKMOF-8-Me (bottom). 
(a)

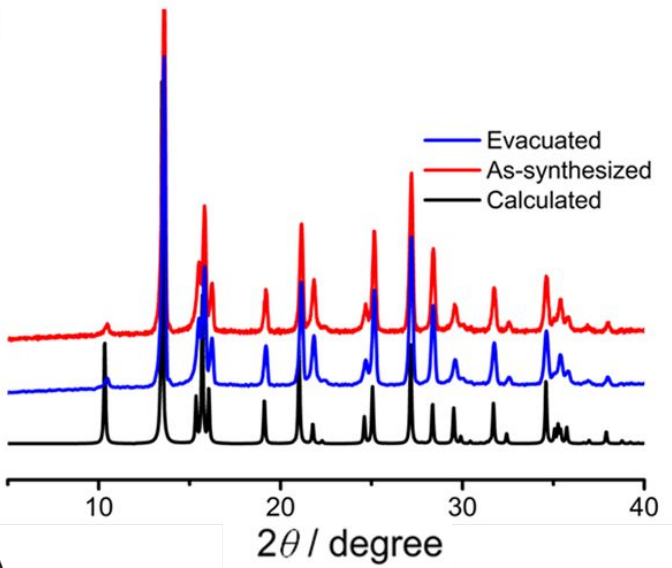

(c)

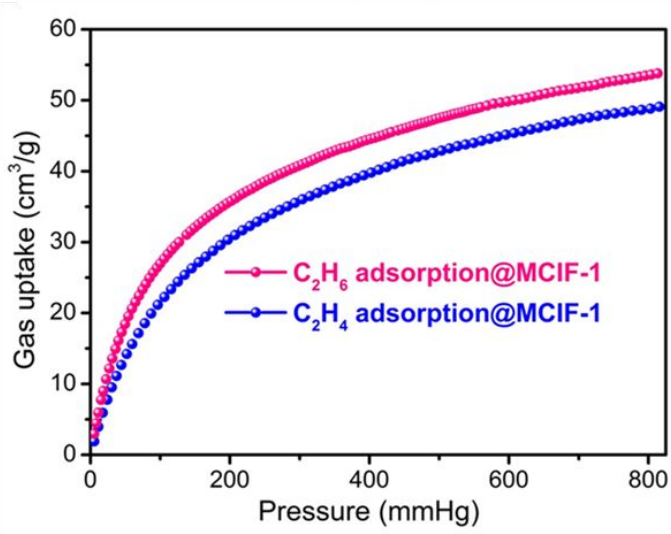

(b)

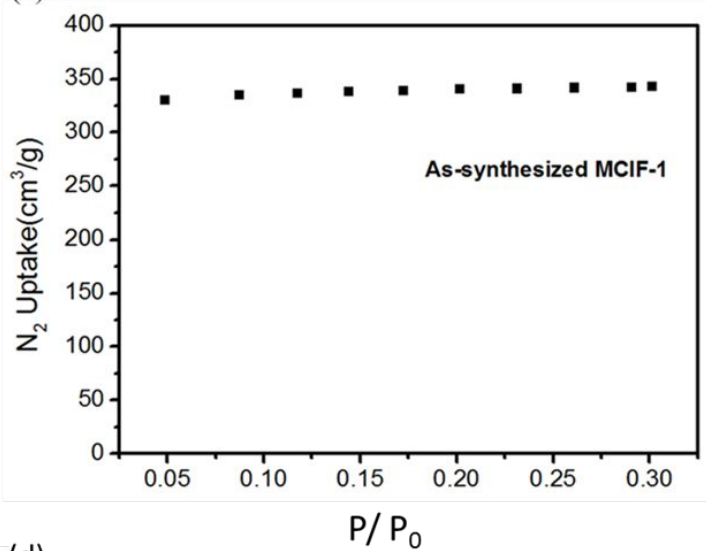

(d)

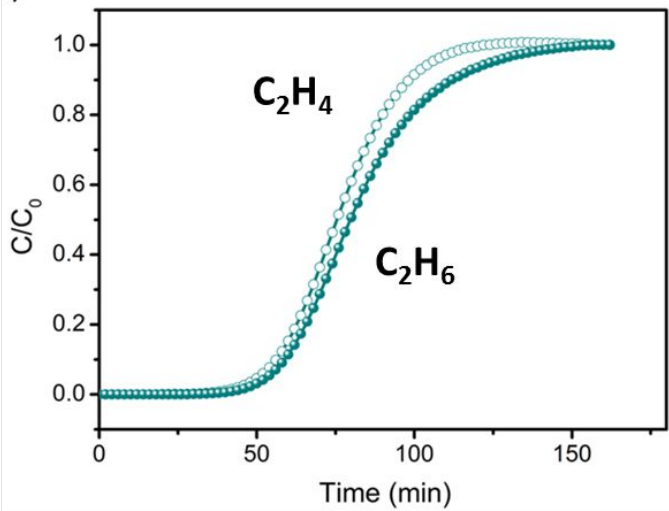

Figure S22. (a) PXRD patterns of MCIF-1. (b) BET data of MCIF-1. (c) The $\mathrm{C}_{2} \mathrm{H}_{6}$ and $\mathrm{C}_{2} \mathrm{H}_{4}$ adsorption isotherms of MCIF-1. (d) Experimental breakthrough curves of a $\mathrm{C}_{2} \mathrm{H}_{6} / \mathrm{C}_{2} \mathrm{H}_{4}(1: 1, \mathrm{v} / \mathrm{v})$ mixture with He as the carrier gas ( $70 \%$, vol\%) for MCIF-1 at $298 \mathrm{~K}$ and 1 bar. The total flow rate was $3 \mathrm{~mL} / \mathrm{min}$.

\section{References:}

S1 Lin, R. B.; Wu, H.; Li, L.; Tang, X. L.; Li, Z.; Gao, J.; Cui, H.; Zhou, W.; Chen, B. Boosting ethane/ethylene separation within isoreticular ultramicroporous metal-organic frameworks. $J$. Am.Chem. Soc. 2018, 140, 12940-12946.

S2 Qazvini, O, T.; Babarao, R.; Shi, Z. L.; Zhang, Y. B.; Telfer, S. G. A Robust Ethane-trapping metal-organic framework with a high capacity for ethylene purification. J. Am. Chem. Soc. 2019, 141, 5014-5020.

S3 Liao, P. Q.; Zhang, W. X.; Zhang, J. P.; Chen, X. M. Efficient purification of ethene by an ethane-trapping metal-organic framework. Nat. Commun. 2015, 6, 8697-8705.

S4 Pires, J.; Pinto, M. L.; Saini, V. K. Ethane selective IRMOF-8 and its significance in ethane-ethylene separation by adsorption. ACS Appl. Mater. Interfaces 2014, 6, 12093-12099.

S5 Gucuyener, C.; Van den Bergh, J.; Gascon, J.; Kapteijn, F. Ethane/ethene separation turned on its head: selective ethane adsorption on the metal-organic framework ZIF-7 through a gate-opening mechanism. J. Am. Chem. Soc. 2010, 132, 17704-17706.

S6 Bohme, U.; Barth, B.; Paula, C.; Kuhnt, A.; Schwieger, W.; Mundstock, A.; Caro, J.; Hartmann, M. Ethene/ethane and propene/propane separation via the olefin and paraffin 
selective metal-organic framework adsorbents CPO-27 and ZIF-8. Langmuir 2013, 29, 8592-8600.

S7 Pei, J.; Wang, J. X.; Shao, K.; Yang, Y.; Cui, Y.; Wu, H.; Zhou, W.; Li, B.; Qian, G. Engineering microporous ethane-trapping metal-organic frameworks for boosting ethane/ethylene separation J. Mater. Chem. A 2020, 8, 3613-3620.

S8 Li, L.; Lin, R.-B.; Krishna, R.; Li, H.; Xiang, S.; Wu, H.; Li, J.; Zhou, W.; Chen, B. Ethane/ethylene separation in a metal-organic framework with iron-peroxo sites. Science $\mathbf{2 0 1 8}$, 362, 443-446.

S9 Liang, W.; Xu, F.; Zhou, X.; Xiao, J.; Xia, Q.; Li, Y.; Li, Z. Ethane selective adsorbent $\mathrm{Ni}(\mathrm{bdc})(\text { ted })_{0.5}$ with high uptake and its significance in adsorption separation of ethane and ethylene. Chem. Eng. Sci. 2016, 148, 275-281.

S10 Chen, Y.; Wu, H.; Lv, D.; Shi, R.; Chen, Y.; Xia, Q.; Li, Z. Highly adsorptive separation of ethane/ethylene by an ethane selective MOF MIL-142A. Ind. Eng. Chem. Res. 2018, 57, 4063-4069.

S11 Chen, Y.; Qiao, Z.; Wu, H.; Lv, D.; Shi, R.; Xia, Q.; Zhou, J.; Li, Z. An ethane-trapping MOF PCN-250 for highly selective adsorption of ethane over ethylene. Chem. Eng. Sci. 2018, 175, $110-117$.

S12 Zeng, H.; Xie, X. J.; Xie, M.; Huang, Y. L.; Luo, D.; Wang, T.; Zhao, Y.; Lu, W.; Li, D. A cage-interconnected metal-organic framework with tailored apertures for efficient $\mathrm{C}_{2} \mathrm{H}_{6} / \mathrm{C}_{2} \mathrm{H}_{4}$ separation under humid conditions. J. Am. Chem. Soc. 2019, 141, 20390-20398.

S13 Cao, H.; Lu, Z.; Kim, H.; Chang, I.; Wang, Y.; Xin, Z.; Duan, J.; Jin, W.; Enhanced breakthrough efficiency by a chemically stable porous coordination polymer with optimized nanochannel. ACS Appl. Mater. Interfaces 2018, 10, 39025-39031.

S14 Zhu, B., Cao J., Mukherjee S., Pham T., Zhang T., Wang T., Jiang X., Forrest K. A., Zaworotko M. J., Chen K. Pore engineering for one-step ethylene purification from a three-component hydrocarbon mixture. J. Am.Chem. Soc. 2021, 143, 1485-1492.

S15 Zhao, N.; Li, P.; Mu, X.; Liu, C,; Sun, F.; Zhu, G. Facile synthesis of an ultra-stable metal-organic framework with excellent acid and base resistance. Faraday Discuss., 2017, 201, 63-70.

S16 Mayo, S. L.; Olafson, B. D.; Goddard, W. A. DREIDING: A generic force field for molecular simulations. J. Phys. Chem. 1990, 94, 8897-8909.

S17 Rappe, A. K.; Casewit, C. J.; Colwell, K. S.; Goddard, W. A.; Skiff, W. M. A full periodic table force field for molecular mechanics and molecular dynamics simulations. J. Am. Chem. Soc. 1992, 114, 10024-10035.

S18 Dubbeldam, D.; Calero, S.; Vlugt, T. J. H.; Krishna, R.; Maesen, T. L. M.; Smit, B. United atom force field for alkanes in nanoporous materials. J. Phys. Chem. B 2004, 108, 12301-12331.

S19 Ban, S.; Laak, A. V.; Jongh, P. E.; Eerden, J. P. J. M.; Vlugt, T. J. H. Adsorption selectivity of benzene/propene mixtures for various zeolites. J. Phys. Chem. C 2007, 111, 17241-17248.

S20 Myers, A. L.; Prausnitz, J. M. Thermodynamics of mixed-gas adsorption. AIChE. J. 1965, 11, 121-127.

S21 Yang, R. T. Gas separation by adsorption processes. Imperial College Press: London, 1986.

S22 Whittaker, E. T.; Robinson, G. The Calculus of Observations: A treatise on numerical mathematics, 4th Ed. Dover: New York, 1967, 84-87. 
